\title{
Heterogeneous resource management in energy hubs with self-consumption: contributions and application example
}

\author{
Jerónimo Ramos-Teodoro ${ }^{\mathrm{a}, *}$, Francisco Rodríguez ${ }^{\mathrm{a}}$, Manuel Berenguel ${ }^{\mathrm{a}}$, José Luis Torres ${ }^{\mathrm{b}}$ \\ ${ }^{a}$ CIESOL-ceiA3, Department of Informatics, University of Almeria, 04120 La Cañada, Almeria, Spain \\ ${ }^{b}$ CIESOL-ceiA3, Department of Engineering, University of Almeria, 04120 La Cañada, Almeria, Spain
}

\begin{abstract}
The energy hub concept and modeling methodology are widely employed tools for solving resource conversion and storage scheduling problems. For instance, industrial clusters might benefit from determining the suitable time to operate their facilities and to sell electricity to the public power grid, according to legal, economic or environmental factors. In this paper, novel elements are introduced in order to more accurately represent real plants and to reduce the amount of decision variables. The major innovation is to consider devices consuming a resource which is not related to the quantity of output produced, by attaching binary decision variables to certain energy hub outputs. Secondly, a path vector is defined to take into account the flows of resources within the system instead of employing a variable for each branch between the components. The third innovation consists of an additional vector to express the amount of output resources sold from the energy hub, including constraints for those resources which are exported and imported through the same medium. An extended energy hub model is first proposed and then applied to a real plant example, including multiple and heterogeneous resources and performing a comparison between days with different demands, weather conditions and electricity prices. The results obtained in the selected scenarios demonstrate a logical operation scheduling, and therefore validate the proposed approach.
\end{abstract}

Keywords: multi-energy systems, scheduling optimization, economic dispatch, industrial cluster

\section{Introduction}

Over the last few years, energy policies aimed at increasing efficiencies in production, transportation, consumption and storage processes have led to approaches based on decentralizing these processes and combining different kinds of energy to benefit from the use of available local resources and infrastructure in a synergistic way. Consequently, renewable energies are expected to play a key role given their relevance in distributed generation either for power networks [1] or combined energy systems [2]. However, because of their intermittent nature, many require storage systems and management strategies that decouple generation from demand in order to be economically viable [3].

On the one hand, recent concepts such as distributed multi-generation (DMG) [4] and multi-energy systems (MES) [5] have come to set a general research framework to manage systems that include various energy carriers and integrating them in demand response programs [6]. Within the so-called MES, the

\footnotetext{
${ }^{*}$ Corresponding author

Email addresses: jeronimo.rteual .es (Jerónimo Ramos-Teodoro), frrodrig@ual .es (Francisco Rodríguez), beren@ual.es (Manuel Berenguel), jltmoreno@ual.es (José Luis Torres)
} 
energy hub approach is widely used as a simplified model for the interactions inside diverse complexity systems relating to their input-output structure. A formal definition of the energy hub concept was given for the first time by Geidl et al. [7] in 2007: a unit where multiple energy carriers can be converted, conditioned, and stored. At the same time, its usage was exemplified in a resource dispatch problem [8]. Since then, many authors have applied this concept to different problems, such as resource management, introducing robust optimization algorithms [9], methodologies to enhance the representation of operational constraints [10] or to facilitate the automatic modeling of arbitrary energy hub configurations [11], and load management strategies [12]. In addition, the energy hub modelling framework has been implemented in microgrid management problems [13], including its integration into vehicle to grid systems [14]. The concept is also used in problems related to economic dispatch [15] or optimal device configuration in systems with [16] or without [17] storage elements. A recent review on common resources and converters in energy hub models [18] shows that most works focus on electricity and thermal heating technologies, paying less attention to other material resources (such as solid fuels, water, carbon dioxide or hydrogen); this makes them interesting from the research point of view. Since energy hub models can be used for both energy and material flows, the term "resource" will be used to refer to them from now on.

One existing obstacle is that legal frameworks for MES networks are still under development and each resource supply and distribution network usually operates under its own rules. Electricity power systems have one of the most extensive legal frameworks, which has set the fundamental basis for smart grid development [19]; this has been thanks to recent advancements in information and communication technologies, as well as those in automation and electronics. For instance, in the Spanish context, some works have already dealt with microgrid management and its integration into the electricity market as a system agent (both as a direct consumer and producer) [20]. Regarding indirect consumers, who are not considered market agents and therefore do not participate in the electricity market, the most recent law regulating self-consumption [21] was approved in 2015, establishing two sorts of self-consumers (depending on the facility features and the contract holder), as described below. Thus, in spite of the legal differences between countries, self-consumption and renewable-based systems become an interesting consideration for small industries [22] and for commercial [23] or residential buildings [24], because of their potential economic and environmental benefits [25].

In view of the above, this paper attempts to address the gap in previous formulations for representing systems of diverse nature and complexity by presenting a widely applicable generic modelling framework. With regard to the formulations made by Parisio et al. [9] and Evins et al. [10], the approach proposed in [12] is a good starting point to include flexible loads (energy hub outputs) although the constraints proposed result in a non-linear formulation of the problem. Similarly, the methodology recently proposed in [11] simplifies the implementation of models, yet it augments the number of decision variables and therefore the size of the matrices which represent the system. Owing to the scarcity of works centered on certain material resources [18], an industrial cluster integrating them will serve as an energy hub example. To provide a real and captivating application for the developed approach, (without loss of generality), the legal situation in Spain concerning type 2 self-consumers is considered, in which sales to the grid are allowed at the pool price and both the self-consumed energy and that sold to the grid are taxed. Consequently, the main contributions can be summarized in the list below:

1. Complementing previous models in order to include the possibility of representing more accurately certain processes, such as selling output resources and adding loads related to the operating state (on/off) of certain devices, which ensures more economical results; and to reduce the number of decision variables for modeling complex energy hubs, which entails reducing the computation effort.

2. Providing an energy hub modelling example, with multiple material and energetic resources, which 
includes unusual inputs (such as seawater and biomass), outputs $\left(\mathrm{CO}_{2}\right.$ enrichment for a greenhouse [26]), and converters (a solar-powered desalination plant and an absorption chiller).

3. Testing the proposed approach's validity using simulation on two different cases for systems with selfconsumption, in which operational scheduling is determined considering variations in the electricity price throughout the day.

The remainder of this paper is organized as follows. Section 2 contains a detailed formulation of a general energy hub, distinguishing between conversion and storage models. Section 3 summarizes the Spanish self-consumption regulations, daily and intraday electricity markets and briefly describes the testbed plant representative of an industrial cluster. In Section 4, the results from various simulation scenarios of the presented energy hub are shown and discussed. Finally, Section 5 highlights the concluding remarks and proposes future lines of research.

\section{Extended energy hub model}

In broad terms, energy hub models are obtained from energy and mass balances between different input and output resource flows. These flows are represented mathematically through variables which constitute the respective input and output vector elements. First formulations [8] defined the so-called coupling matrix in order to establish the relationship between them. Additional introduced terms are required when storage elements appear, so there is usually a distinction between the conversion and storage model [9]. The systems represented are supposed to contain their devices close enough to assume that resource losses only occur in conversion and storage processes. In order to formulate a linear model, the use of dispatch factors [8] must be avoided; thus Parisio et al. [9] suggested introducing as many variables as there are conversion devices, rearranging the input vector and the coupling matrix in a new equation which relates them to the output vector. A similar approach was adopted by Evins et al. [10] which combined an input-output equation with the one proposed by Parisio et al. [9].

Considering the most common elements in previous approaches (represented in black in Fig. 1), the conversion and storage model of a general energy hub is formulated which comprises $N_{i}$ inputs, $N_{o}$ outputs, and $N_{d}$ Single-Input and Single-Output (SISO) conversion devices. The equation represents the system in discrete time using a uniform sample time $T=t(k+1)-t(k)$, where $k$ constitutes any time instant. All the novel elements introduced have been highlighted in blue in Fig. 1 and justified below.

\subsection{Additional formulations for the conversion model}

Firstly, in contrast to the model in [9] a path vector $\boldsymbol{P}=\left[\begin{array}{lll}P_{1} & \cdots & P_{N_{p}}\end{array}\right]^{T}$ is defined. It contains a variable for each possible path between inputs and outputs ( $N_{p}$ in total), and therefore its size depends on the energy hub internal structure. In this way, it is possible to formulate the conversion model of complex energy hubs more simply and to reduce the amount of decision variables. Considering this definition, the inputs-paths relationship is obtained (1):

$$
\boldsymbol{I}(k)=\boldsymbol{C}_{\boldsymbol{i}} \boldsymbol{P}(k)
$$

by means of the input vector $\boldsymbol{I}=\left[\begin{array}{lll}I_{1} & \cdots & I_{N_{i}}\end{array}\right]^{T}$, the path vector $\boldsymbol{P}$ and the input coupling matrix $\boldsymbol{C}_{\boldsymbol{i}}$, which does not depend on time; it is a constant matrix of zeros and ones to express the sum of $\boldsymbol{P}$ elements corresponding to each input resource.

Besides this, the balance between input, output and storage systems is established as follows (2):

$$
\boldsymbol{\delta}_{\boldsymbol{O}}(k) \boldsymbol{O}(k)+\boldsymbol{M}(k)=\boldsymbol{C}(k) \boldsymbol{P}(k)-\boldsymbol{Q}_{\boldsymbol{c h}}(k)+\boldsymbol{Q}_{\boldsymbol{d i s}}(k)
$$




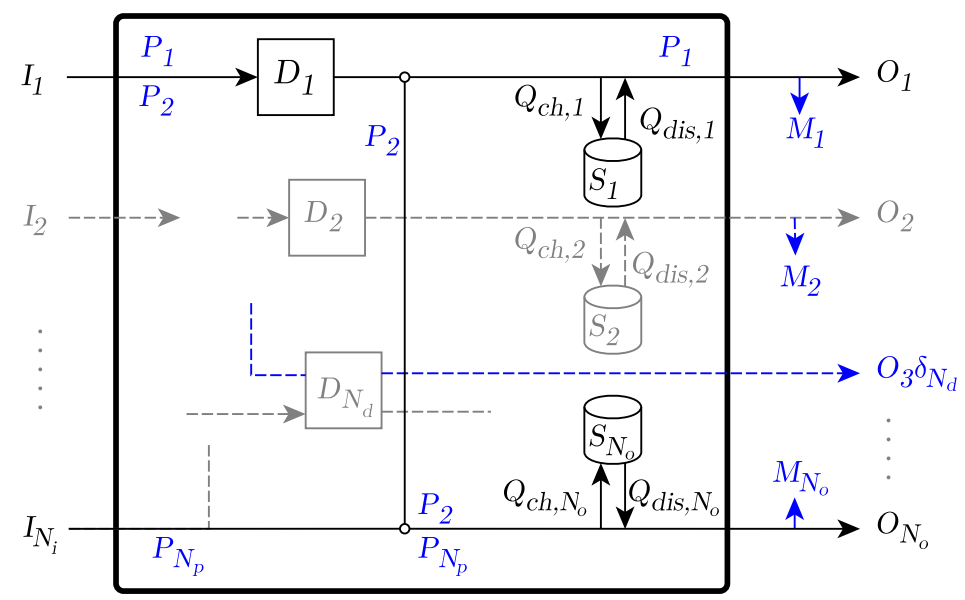

Figure 1: Schematic diagram of a general energy hub with storage at the output ports. The novel elements introduced in this paper are highlighted in blue: binary variables attached to certain outputs, paths between the inputs and outputs, and output resource sales.

where the output vector $\boldsymbol{O}=\left[\begin{array}{lll}O_{1} & \cdots & O_{N_{o}}\end{array}\right]^{T}$ is related to the product of the path vector $\boldsymbol{P}$ and the coupling matrix $\boldsymbol{C}$, the charge vector $\boldsymbol{Q}_{\boldsymbol{c h}}=\left[\begin{array}{lll}Q_{c h, 1} & \cdots & Q_{c h, N_{o}}\end{array}\right]^{T}$ and the discharge vector $\boldsymbol{Q}_{\text {dis }}=$ $\left[\begin{array}{lll}Q_{d i s, 1} & \cdots & Q_{d i s, N_{o}}\end{array}\right]^{T}$. With respect to the model presented in [9], a market sales vector, as a new load or demand with associated revenues, $\boldsymbol{M}=\left[\begin{array}{lll}M_{1} & \cdots & M_{N_{o}}\end{array}\right]^{T}$ and the output activation matrix $\boldsymbol{\delta}_{\boldsymbol{O}}$ are introduced.

The use of the market sales vector $\boldsymbol{M}$ is justified because of the differences in purchase and selling prices of each kind of resource, so it would not be suitable to use negative values in vector $\boldsymbol{I}$ to represent resource sales instead. Furthermore, by making $\delta_{O}$ a diagonal matrix containing ones and binary decision variables, loads which depend on the on/off state of certain conversion or storage devices can be included in the output vector. The binary variables are those related to each output, such as $\delta_{N_{d}}$ and $O_{3}$ in Fig. 1 , whereas the remaining coefficients, equal to one, do not modify the outputs. From a practical viewpoint, this constitutes a tool to decide when a device consuming a resource without converting it must operate or not. A desalination plant and a pump to compress $\mathrm{CO}_{2}$, will serve as examples in the next section.

Apart from this, another expression is needed to establish resource flows through converters (3):

$$
\boldsymbol{D}(k)=\boldsymbol{C}_{\boldsymbol{d}}(k) \boldsymbol{P}(k)
$$

Thanks to the device coupling matrix $\boldsymbol{C}_{\boldsymbol{d}}$, device vector $\boldsymbol{D}=\left[\begin{array}{lll}D_{1} & \cdots & D_{N_{d}}\end{array}\right]^{T}$ is obtained from path vector $\boldsymbol{P}$. Depending on the $\boldsymbol{C}_{\boldsymbol{d}}$ definition $\boldsymbol{D}$ may refer to the input or the output flows of each device.

Owing to input or selling resource availability and production limits in converters, restrictions are required for inputs (4), sales (5) and devices (6):

$$
\begin{gathered}
I_{i}^{\min }(k) \delta_{I, i}(k) \leq I_{i}(k) \leq I_{i}^{\max }(k) \delta_{I, i}(k), \\
M_{o}^{\min }(k) \delta_{M, o}(k) \leq M_{o}(k) \leq M_{o}^{\max }(k) \delta_{M, o}(k), \\
D_{d}^{\min }(k) \delta_{D, d}(k) \leq D_{d}(k) \leq D_{d}^{\max }(k) \delta_{D, d}(k),
\end{gathered}
$$

with $i=1, \ldots, N_{i}, o=1, \ldots, N_{o}$, and $d=1, \ldots, N_{d}$. As mentioned above, variables $I_{i}$ and $M_{o}$ refer, respectively, to the resource flow of any input $i$ and the resource flow of any market sale $o$ of the energy 
hub, whereas variable $D_{d}$ refers to the resource flow of any device $d$ whose value depends on the energy hub structure (exemplified in the next section). In the case of devices requiring restrictions both for the input and the output flow, just by adding conversion factors to $C_{d}$ and two equations analogous to the balance between input, outputs and storage (2) and the devices limits (6), it is possible to have a device vector referred to inputs and another one referred to outputs with their respective constraints.

All these variables are delimited by their lower (denoted with superscript $\min$ ) and upper limits (denoted with superscript $\max$ ). $\delta_{M, o}, \delta_{I, i}$ and $\delta_{D, d}$ constitute binary decision variables which determine, respectively, whether an input $i$, market sale $o$ or converter $d$ is active or not.

Finally, additional constraints must be included in case input $i$ and selling resources $o$ share a network (a typical situation in power and water supply) to prevent simultaneous flows in $I_{i}$ and $M_{o}$ (7),

$$
\delta_{I, i}(k)+\delta_{M, o}(k) \leq 1,
$$

with $i$ and $o$ sharing a network whenever two or more devices cannot operate simultaneously (8):

$$
\delta_{D, d^{(1)}}(k)+\cdots+\delta_{D, d^{(n)}}(k) \leq 1,
$$

with $d^{(1)} \ldots d^{(n)}$ corresponding to non-simultaneous converters or if a device has more than one output (9),

$$
P_{p^{(1)}}(k)+\ldots+P_{p^{(n)}}(k)=P_{p^{(n+1)}}(k)+\ldots+P_{p^{(m)}}(k),
$$

with $p^{(1)} \ldots p^{(n)} \ldots p^{(m)}$ corresponding to simultaneous converter outputs. Although these three situations are exemplified in the next section, for a better understanding the following explanations are provided:

- In the first case (7), when an input resource (e.g. electricity) is supplied from a public utility network through a certain medium, the supply facility (e.g. electrical wiring) cannot be employed at the same time for selling resources since this means establishing a flow in the opposite direction.

- In the second case (8), if for any reason two devices cannot operate together (e.g. a device virtually split into two different ones, such as a reversible heat pump), the flows through each can be limited by making their corresponding binary variable equal to zero.

- In the third case (9), some devices can supply different output resources from their input (e.g. a combined heat and power system), so although each produced resource constitutes a different path in $\boldsymbol{P}$, their upstream flow is the same (the fuel input) and so are the sums of elements in $\boldsymbol{P}$ corresponding to each output of the device.

\subsection{Storage model}

In order to properly meet resource demands, most previous models in the literature introduce storage devices, as represented in Fig. 1. The storage dynamic is assumed to be linear and, without loss of generality [27], devices are considered to be located only at the output flows, so the storage balance is stated as (10):

$$
\boldsymbol{S}(k+1)=\boldsymbol{L}(k) \boldsymbol{S}(k)+\boldsymbol{C}_{\boldsymbol{c h}}(k) \boldsymbol{Q}_{\boldsymbol{c h}}(k)-\boldsymbol{C}_{\boldsymbol{d i s}}(k) \boldsymbol{Q}_{\boldsymbol{d i s}}(k)
$$

where storage vector $\boldsymbol{S}=\left[\begin{array}{lll}S_{1} & \cdots & S_{N_{o}}\end{array}\right]^{T}$ at sample $k+1$ relates to the storage amount at sample $k$ multiplied by the degradation matrix $\boldsymbol{L}=\operatorname{diag}\left(\eta_{l, 1} \quad \cdots \quad \eta_{l, N_{o}}\right)$, and the product of the charge $\boldsymbol{Q}_{\boldsymbol{c h}}$ and discharge $\boldsymbol{Q}_{\boldsymbol{d i s}}$ flows plus their respective charge $\boldsymbol{C}_{\boldsymbol{c h}}=\operatorname{diag}\left(\eta_{c h, 1} \cdots \eta_{c h, N_{o}}\right)$ and discharge $\boldsymbol{C}_{\boldsymbol{d i s}}=\operatorname{diag}\left(1 / \eta_{\text {dis }, 1} \quad \cdots \quad 1 / \eta_{d i s, N_{o}}\right)$ performance matrices. Notice that the degradation matrix $\boldsymbol{L}$ is introduced to take into account the storage percentage losses, as in [10]. 
In addition, it is necessary to set limits both for the charge (11) or discharge (12) flows, and for the storage capacity (13) as well as to prevent charge and discharge flows from occurring simultaneously (14):

$$
\begin{gathered}
Q_{c h, o}^{\min }(k) \delta_{c h, o}(k) \leq Q_{c h, o}(k) \leq Q_{c h, o}^{\max }(k) \delta_{c h, o}(k), \\
Q_{d i s, o}^{\min }(k) \delta_{d i s, o}(k) \leq Q_{d i s, o}(k) \leq Q_{d i s, o}^{\max }(k) \delta_{d i s, o}(k), \\
S_{o}^{\min }(k) \leq S_{o}(k) \leq S_{o}^{\max }(k), \\
\delta_{c h, o}(k)+\delta_{d i s, o}(k) \leq 1,
\end{gathered}
$$

with $o=1, \ldots, N_{o}$. In these lasts equations, variables $Q_{c h, o}, Q_{d i s, o}$, and $S_{o}$ have already been defined as the charge and discharge flows and the storage state of any output $o$, whereas superscripts $\min$ and $\max$ are used again for their lower and upper limits. Binary variables $\delta_{c h, o}$ and $\delta_{d i s, o}$ determine if device $o$ is charging, discharging or standing by.

\section{Case study: an experimental industrial cluster}

\subsection{Test-bed plant description}

The industrial cluster [28], employed to exemplify this approach and clarify the proposed extensions in the energy hub model, includes the Center for Solar Energy Research (CIESOL) building, the photovoltaic $(\mathrm{PV})$ parking and the electric vehicle located at the University of Almeria campus, a desalination plant at the facilities of the Almeria Solar Platform (PSA) research center and a greenhouse at the Cajamar Experimental Station. Although these facilities are physically apart, they are considered a single ensemble which can be modelled under the energy hub framework since their devices can convert, interchange and store resources, as shown in figure 2. In addition, the size of the whole system, the kind of resources interchanged, and the presence of elements such as the greenhouse and the desalination plant allows its designation as an industrial cluster.

A full description of the plant can be found in [29] but, for the purpose of this work, only the most relevant devices, whose technical characteristics are taken into account to establish the operational limits and conversion factors described in Section III, will be mentioned:

- The CIESOL production system is made up of 42 Atersa A-222P photovoltaic modules connected to 3 CICLO-3000 inverters, 80 Solaris CP1 flat-plate solar collectors, a Yazaki WFC SC20 absorption chiller and a Ciatesa Hidropack WE 360 reversible heat pump. Thus, the building can provide both electricity and thermal power (either heating or cooling). Previous works contain detailed descriptions of the building's components [30] and its control system [31].

- The parral-type greenhouse [32] has a total surface area of $877 \mathrm{~m}^{2}(37.8 \mathrm{~m} \times 23.2 \mathrm{~m})$ and its heating system consists of a GP 95 propane heater and a Missouri 150000 multi-fuel boiler fed with biomass, which can also supply $\mathrm{CO}_{2}$ to enhance crop growth [26].

- The AQUASOL system [33] comprises a multiple-effect distillation (MED) plant and a double-effect steam absorption chiller manufactured by Entropie, a solar field made up of 252 CPC Ao Sol 1.12× stationary solar collectors and an ATTSU RL200 propane boiler. The last two supply the thermal energy required for desalination. 


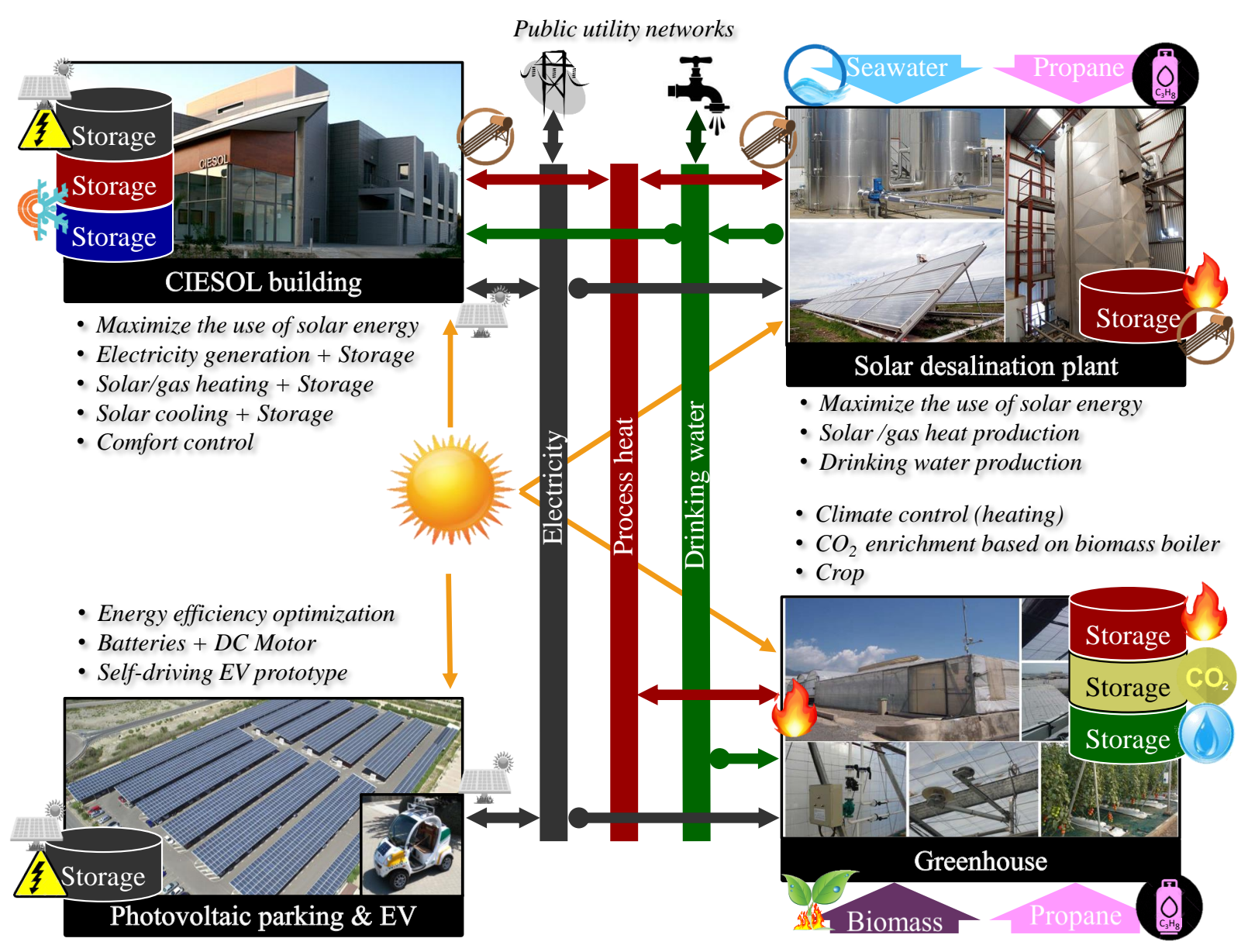

Figure 2: Functional diagram of the test-bed plant [28]. Each facility can demand, supply and store different resources: CIESOL and the parking area can produce electricity through their photovoltaic systems, for themselves and for the rest of the cluster; heat is generated from the solar collector facilities; combustion equipment (with a $\mathrm{CO}_{2}$ capture system for the greenhouse), or the HVAC system in CIESOL (which can also provide cooling for the building) and the desalination plant can produce drinking water, required both by the greenhouse and CIESOL. The public electricity and water utility network can serve as a backup or allow the sale of surplus resources.

- The photovoltaic parking consists of 4830 Conergy PA 240P modules connected to 10 Fronius Agilo 100 inverters, as well as three groups of modules connected to their respective Fronius IG Plus 55v3 inverters, which are distributed as follows: 24 Conergy PA 240P modules in the first group, 24 Conergy Power Plus 240M modules in the second and 72 First Solar FS-380 modules in the third. The nominal power of the facility is $1015 \mathrm{~kW}$.

Since each facility has its own database, all data need to be cleaned, synchronized and analyzed to determine the demand or load profiles of each resource type as well as to model the converter devices. Furthermore, the hourly electricity price data for daily and intraday markets were acquired from the OMIE website [34]. This was done for the 2013-2017 period to have a wide enough set of data available from which to select specific days for simulations. In addition, this work is based on the ENERPRO and CHROMAE research projects, funded by the Spanish Ministry of Economy, Industry and Competitiveness and ERDF funds. A different formerly adopted approach [35] led to the current formulation of the problem em- 
ploying mixed integer linear programming (MILP). A set of functions, programmed in MATLAB ${ }^{\circledR}$, allows us to determine a suitable resource schedule for the energy hub.

\subsection{Spanish self-consumption regulations and electricity market}

The Royal Decree 900/2015 [21] regulates Spanish electricity supply and generation for self-consumption; this is defined as the electric power consumption from either the facilities placed within a consumer's grid or a direct power line associated to a consumer. The decree applies to any renewable generation facility connected in some way to the public grid but not to isolated ones. Two kinds of self-consumption are distinguished, the main features of which are summarized as follows:

1. Self-consumers type 1 , whose facilities are placed within a grid on their property and which are registered solely for self-consumption (not production). The capacity is limited to $100 \mathrm{~kW}$ and the owner of the facilities must also be the holder of the power purchase agreement. Energy is only generated for self-consumption and although surplus energy can be exported through the public grid, it is not economically remunerated.

2. Self-consumers type 2, whose facilities are registered as production facilities (in addition to selfconsumption facilities). The owner and the holder of the power purchase agreement do not have to be the same legal entity. Surplus energy can be indirectly sold through retailers (who are in charge of purchasing the energy excess which they will benefit from by selling it to other consumers)at the pool price, discounting a generation fee of $0.5 € / \mathrm{MWh}$ [36] and a $7 \%$ tax (IVPEE) [37] on the production.

In both cases the maximum power must coincide with that contracted with the power supply company. Consumers are also subjected to access charges which are determined yearly [38] and depend on the contracted power and the period of the day: variable charges $(€ / \mathrm{kWh})$ for the amount of self-consumed energy and fixed charges $(€ / \mathrm{kW})$ for the difference between the demanded power and the contracted power (mainly applied to systems including batteries).

With regard to the Spanish electrical power system, this is operated by two independent entities: the market operator, OMI-Polo Español, S.A. (OMIE) [39], which performs the economic management of the daily and intraday markets; and the system operator, Red Eléctrica de España, S.A. (REE) [40], which is in charge of technical issues such as determining the feasibility of the dispatch provided by OMIE (thus affecting the final scheduling and price). Both companies are involved in the market transactions but they do not participate directly in buying or selling electricity.

As in the rest of the European Union, the daily market is a marginal pricing market: hourly prices and trading volumes are set at the point where the supply and demand curves meet. Considering Coordinated Universal Time (UTC) according to daylight saving time (DST, which implies using UTC +1 in winter and UTC +2 in summer), purchase and sale bids for the next day must be presented by agents to the market operator before 12:00 $\mathrm{h}$ for them to be included in a matching procedure (carried out by the Euphemia algorithm [41]). Then the results are sent to the system operator to check the technical viability. The Matching Basis Daily Schedule (MBDS) is published before 13:00 h and updated three times a day, attending to technical and administrative constraints: the Operating Basis Daily Schedule (OBDS) before 14:00 h, the Provisional Viable Daily Schedule (PVDS) before 16:00 h, and the Final Viable Daily Schedule (FVDS) before 17:00 h.

On the other hand, the purpose of the intraday market is to adjust the Final Viable Daily Schedule by again presenting the sale and purchase bids. Only agents who have previously participated in the daily market session can submit bids, and they can only do it for the same hourly periods in which they have participated. This is structured into six sessions, as presented in Table 1 and Fig. 3, which end with the 
publication of the Final Hourly Schedule (FHS); thus, prices are updated twice before the day begins and four times (taking into account the three first hours of the first session) before the day ends.

Table 1: Intraday market schedule (UTC+1/UTC+2) [39]

\begin{tabular}{lcccccc}
\hline \hline Session number & 1 & 2 & 3 & 4 & 5 & 6 \\
\hline Session opening & $17: 00$ & $21: 00$ & $01: 00$ & $04: 00$ & $08: 00$ & $12: 00$ \\
Session closing & $18: 45$ & $21: 45$ & $01: 45$ & $04: 45$ & $08: 45$ & $12: 45$ \\
Matching results & $19: 30$ & $22: 30$ & $02: 30$ & $05: 30$ & $09: 30$ & $13: 30$ \\
Breakdowns & $19: 50$ & $22: 50$ & $02: 50$ & $05: 50$ & $09: 50$ & $13: 50$ \\
FHS publication & $20: 45$ & $23: 45$ & $03: 45$ & $06: 45$ & $10: 45$ & $14: 45$ \\
Schedule horizon & $27 \mathrm{~h}$ & $24 \mathrm{~h}$ & $20 \mathrm{~h}$ & $17 \mathrm{~h}$ & $13 \mathrm{~h}$ & $9 \mathrm{~h}$ \\
Hourly periods & $22-24$ & $1-24$ & $5-24$ & $8-24$ & $12-24$ & $16-24$ \\
\hline \hline
\end{tabular}

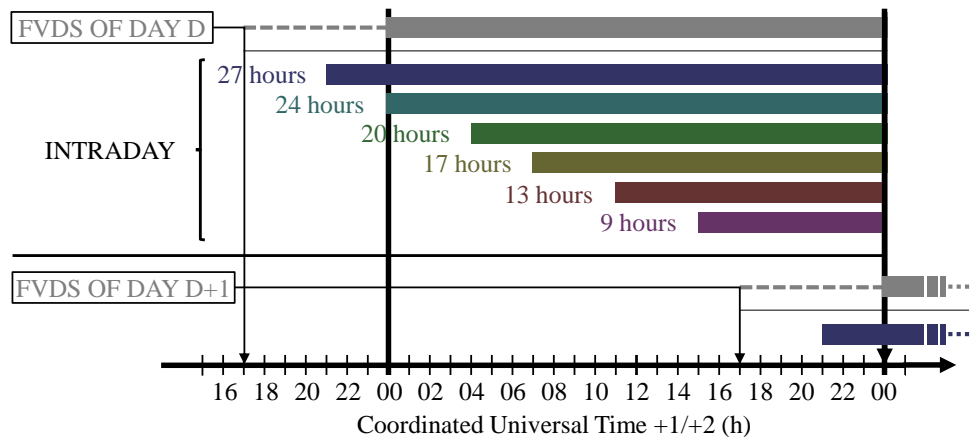

Figure 3: Daily market and intraday market distribution [39]. Time axis label refers to both summer (UTC+2) and winter periods $(\mathrm{UTC}+1)$.

\subsection{Modeling under the energy hub approach}

This subsection constitutes a real application example of the extended energy hub model proposed in Section 2. In the industrial cluster described above, and depicted in Fig. 2, resources can be identified as inputs or outputs depending on their origin and destination. In broad terms, inputs comprise raw materials and outputs by load or demand from any of the facilities. These, together with the conversion and storage devices for each facility, form the energy hub illustrated in Fig. 4. The following paragraphs provide details of the elements in equations (1) to (14) particularized for this example.

\subsubsection{Decision variables and constraints}

Fig. 4 represents the example case, which consists of an energy hub with eight inputs and nine outputs, three of which coincide with resources available for sale (a description of each is offered in Table 2). Moreover, considering the SISO converters so as to be able to set suitable constraints, and therefore to have two independent converters for both the greenhouse biomass boiler and the CIESOL reversible heat pump, a total amount of twelve converters (numbered within parentheses in Fig. 4) can be identified. Different resource flows are distinguished by colors, as indicated in the legend, and nodes are employed to discern converging or diverging flows from any other crossing line caused by picturization. As in the general model, input, output, charge, discharge, market sales, and storage vectors are defined based on top to bottom input 


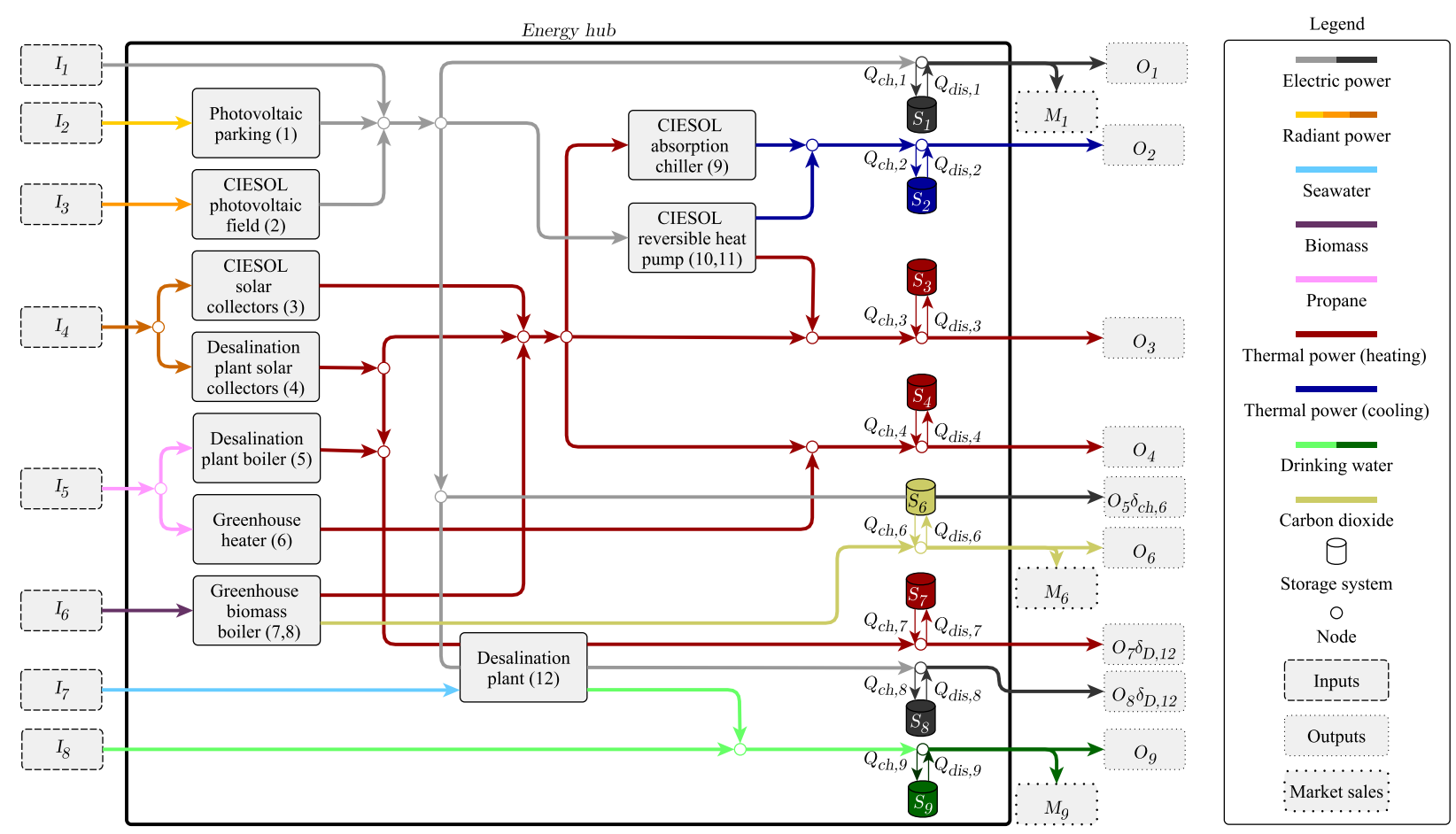

Figure 4: Schematic diagram of the real energy hub example. The individual equipment for each facility constitutes the conversion devices, whereas the public utility networks can interchange resources through $I_{1}, I_{8}, M_{1}$, and $M_{8}$. Some resources are represented by different colors, depending on the variables associated to them, in order to clarify the results in the following figures.

and output resources. Radiant power has been split into three different inputs because each has a different economic cost (remember, photovoltaic generation for self-consumption is taxed).

According to Fig. 4, only electricity, $\mathrm{CO}_{2}$ and water sales are allowed, and there is no storage system for the electricity required by the $\mathrm{CO}_{2}$ compression pump. Thus, for the sake of simplicity, the variables $M_{2}, M_{3}, M_{4}, M_{5}, M_{7}, M_{8}, S_{5}, Q_{c h, 5}$, and $Q_{d i s, 5}$ are not represented in the diagram. However, they still constitute elements of the market sales, storage, charge, and discharge vectors, so the upper and lower limits of these variables have to be zero. Note that $M_{6}$ refers to $\mathrm{CO}_{2}$ released (not sold) as this constitutes an arrangement for avoiding unfeasible solutions when the storage is full.

The missing arrows at the desalination plant (electricity and heat) and $\mathrm{CO}_{2}$ storage input ports indicate that no conversion exists for these flows: they just represent the dependence of loads $O_{5}, O_{7}$ and $O_{8}$ on those devices, as their related binary variables also corroborate. Therefore, in this case, the output activation matrix $\boldsymbol{\delta}_{\boldsymbol{O}}$ is defined as the nine-dimension identity matrix whose elements $(5,5),(7,7)$, and $(8,8)$ have been replaced by $\delta_{c h, 6}, \delta_{D, 12}$, and $\delta_{D, 12}$. The size of matrices $\boldsymbol{C}_{\boldsymbol{i}}, \boldsymbol{C}$ and $\boldsymbol{C}_{\boldsymbol{d}}$ (referring to device inputs) makes their representation difficult; hence they are defined in the appendix using tables containing their non-zero elements and their respective indexes.

With regard to the remaining variables, Table 3 shows the possible paths represented by vector $\boldsymbol{P}$. To avoid confusion, the paths are represented without mathematical notation since their elements do not refer to resource flows.

Equations (7), (8) and (9) must be rearranged to set suitable constraints for the real plant. Firstly, owing to the dependence of the electricity and water supply networks, two constraints are required (15), (16):

$$
\delta_{I, 1}(k)+\delta_{M, 1}(k) \leq 1,
$$


Table 2: Input, output and market variables description

\begin{tabular}{clc}
\hline \hline Variable & Description & $\mathrm{Units}$ \\
\hline$I_{1}$ & Electricity from the public utility network & $\mathrm{kW}$ \\
$I_{2}$ & Radiant power received from parking PV modules & $\mathrm{kW}$ \\
$I_{3}$ & Radiant power received from CIESOL PV modules & $\mathrm{kW}$ \\
$I_{4}$ & Radiant power received from solar collectors & $\mathrm{kW}$ \\
$I_{5}$ & Propane for fossil fuel combustion systems & $\mathrm{kg} / \mathrm{h}$ \\
$I_{6}$ & Wood pellets for the biomass boiler & $\mathrm{kg} / \mathrm{h}$ \\
$I_{7}$ & Seawater for the desalination plant & $\mathrm{m}^{3} / \mathrm{h}$ \\
$I_{8}$ & Drinking water from the public utility network & $\mathrm{m}^{3} / \mathrm{h}$ \\
\hline$O_{1}$ & Electricity for CIESOL and the greenhouse & $\mathrm{kW}$ \\
$O_{2}$ & Thermal power (cooling) for CIESOL & $\mathrm{kW}$ \\
$O_{3}$ & Thermal power (heating) for CIESOL & $\mathrm{kW}$ \\
$O_{4}$ & Thermal power (heating) for the greenhouse & $\mathrm{kW}$ \\
$O_{5}$ & Electricity for the greenhouse CO 2 pump & $\mathrm{kW}$ \\
$O_{6}$ & Carbon dioxide for the greenhouse & $\mathrm{kg} / \mathrm{h}$ \\
$O_{7}$ & Thermal power (heating) for the desalination plant & $\mathrm{kW}$ \\
$O_{8}$ & Electricity for the desalination plant & $\mathrm{kW}$ \\
$O_{9}$ & Water for CIESOL and the greenhouse & $\mathrm{m}^{3} / \mathrm{h}$ \\
\hline$M_{1}$ & Electricity sold through the public utility network & $\mathrm{kW}$ \\
$M_{6}$ & Carbon dioxide released from storage & $\mathrm{kg} / \mathrm{h}$ \\
$M_{9}$ & Water sold through the public utility network & $\mathrm{m} 3 / \mathrm{h}$ \\
\hline \hline
\end{tabular}

Table 3: Vector $\boldsymbol{P}$ Elements for each path in the real plant

\begin{tabular}{cccc}
\hline \hline$P_{p}$ & Path $^{*}$ & $P_{p}$ & Path $^{*}$ \\
\hline$P_{1}$ & $\mathrm{I} 1 \rightarrow \mathrm{O} 1$ & $P_{2}$ & $\mathrm{I} 1 \rightarrow \mathrm{D} 10 \rightarrow \mathrm{O} 2$ \\
$P_{3}$ & $\mathrm{I} 1 \rightarrow \mathrm{D} 11 \rightarrow \mathrm{O} 3$ & $P_{4}$ & $\mathrm{I} 1 \rightarrow \mathrm{O} 8$ \\
$P_{5}$ & $\mathrm{I} 1 \rightarrow \mathrm{O} 5$ & $P_{6}$ & $\mathrm{I} 2 \rightarrow \mathrm{D} 1 \rightarrow \mathrm{O} 1$ \\
$P_{7}$ & $\mathrm{I} 2 \rightarrow \mathrm{D} 1 \rightarrow \mathrm{D} 10 \rightarrow \mathrm{O} 2$ & $P_{8}$ & $\mathrm{I} 2 \rightarrow \mathrm{D} 1 \rightarrow \mathrm{D} 11 \rightarrow \mathrm{O} 3$ \\
$P_{9}$ & $\mathrm{I} 2 \rightarrow \mathrm{D} 1 \rightarrow \mathrm{O} 8$ & $P_{10}$ & $\mathrm{I} 2 \rightarrow \mathrm{D} 1 \rightarrow \mathrm{O} 5$ \\
$P_{11}$ & $\mathrm{I} 3 \rightarrow \mathrm{D} 2 \rightarrow \mathrm{O} 1$ & $P_{12}$ & $\mathrm{I} 3 \rightarrow \mathrm{D} 2 \rightarrow \mathrm{D} 10 \rightarrow \mathrm{O} 2$ \\
$P_{13}$ & $\mathrm{I} 3 \rightarrow \mathrm{D} 2 \rightarrow \mathrm{D} 11 \rightarrow \mathrm{O} 3$ & $P_{14}$ & $\mathrm{I} 3 \rightarrow \mathrm{D} 2 \rightarrow \mathrm{O} 8$ \\
$P_{15}$ & $\mathrm{I} 3 \rightarrow \mathrm{D} 2 \rightarrow \mathrm{O} 5$ & $P_{16}$ & $\mathrm{I} 4 \rightarrow \mathrm{D} 3 \rightarrow \mathrm{D} 9 \rightarrow \mathrm{O} 2$ \\
$P_{17}$ & $\mathrm{I} 4 \rightarrow \mathrm{D} 3 \rightarrow \mathrm{O} 3$ & $P_{18}$ & $\mathrm{I} 4 \rightarrow \mathrm{D} 3 \rightarrow \mathrm{O} 4$ \\
$P_{19}$ & $\mathrm{I} 4 \rightarrow \mathrm{D} 4 \rightarrow \mathrm{D} 9 \rightarrow \mathrm{O} 2$ & $P_{20}$ & $\mathrm{I} 4 \rightarrow \mathrm{D} 4 \rightarrow \mathrm{O} 3$ \\
$P_{21}$ & $\mathrm{I} 4 \rightarrow \mathrm{D} 4 \rightarrow \mathrm{O} 4$ & $P_{22}$ & $\mathrm{I} 4 \rightarrow \mathrm{D} 4 \rightarrow \mathrm{O} 7$ \\
$P_{23}$ & $\mathrm{I} 5 \rightarrow \mathrm{D} 5 \rightarrow \mathrm{O} 7$ & $P_{24}$ & $\mathrm{I} 5 \rightarrow \mathrm{D} 6 \rightarrow \mathrm{O} 4$ \\
$P_{25}$ & $\mathrm{I} 6 \rightarrow \mathrm{D} 7 \rightarrow \mathrm{D} 9 \rightarrow \mathrm{O} 2$ & $P_{26}$ & $\mathrm{I} 6 \rightarrow \mathrm{D} 7 \rightarrow \mathrm{O} 3$ \\
$P_{27}$ & $\mathrm{I} 6 \rightarrow \mathrm{D} 7 \rightarrow \mathrm{O} 4$ & $P_{28}$ & $\mathrm{I} 6 \rightarrow \mathrm{D} 8 \rightarrow \mathrm{O} 6$ \\
$P_{29}$ & $\mathrm{I} 7 \rightarrow \mathrm{D} 12 \rightarrow$ O9 & $P_{30}$ & $\mathrm{I} 8 \rightarrow$ O9 \\
\hline \hline
\end{tabular}

*I: input, O: output, D: device. 


$$
\delta_{I, 8}(k)+\delta_{M, 9}(k) \leq 1 .
$$

In addition, the reversible heat pump is split into two virtual devices which cannot operate at the same time so (17):

$$
\delta_{D, 10}(k)+\delta_{D, 11}(k) \leq 1 .
$$

Finally, since the biomass boiler produces both thermal energy and $\mathrm{CO}_{2}$, consider (18):

$$
P_{25}+P_{26}+P_{27}=P_{28}
$$

where the left term of the equation represents the biomass flow for heat production whereas the right one represents the biomass flow for $\mathrm{CO}_{2}$ production.

\subsubsection{Operation Limits and Conversion Factors}

Except for the solar systems, the upper and lower limits of the conversion devices, summarized in Table 4, correspond to static models based on their datasheet and a previous work for the desalination plant [42]. For storage systems, either hypothetical values are assumed, or values obtained from experimentation are included [26], whereas lower and upper limit inputs are set to zero and infinity, respectively. The market sales vector limits are not tabulated since they are zero for all their elements apart from $M_{1}, M_{6}$, and $M_{9}$ these, together with the input vector elements, have their lower limit set to zero whereas their upper limits

\begin{tabular}{|c|c|c|c|c|c|}
\hline Variable & Min & Max & Variable & Min & Max \\
\hline$D_{5}$ & $0 \mathrm{~kg} / \mathrm{h}$ & $20 \mathrm{~kg} / \mathrm{h}$ & $\bar{S}$ & $0 \mathrm{kWh}$ & $11 \mathrm{kWh}$ \\
\hline$D_{6}$ & $0 \mathrm{~kg} / \mathrm{h}$ & $6.8 \mathrm{~kg} / \mathrm{h}$ & $S_{2}$ & $0 \mathrm{kWh}$ & $29 \mathrm{kWh}$ \\
\hline$D_{7}$ & $15 \mathrm{~kg} / \mathrm{h}$ & $40 \mathrm{~kg} / \mathrm{h}$ & $S_{3}$ & $0 \mathrm{kWh}$ & $174.2 \mathrm{kWh}$ \\
\hline$D_{8}$ & $15 \mathrm{~kg} / \mathrm{h}$ & $40 \mathrm{~kg} / \mathrm{h}$ & $S_{4}$ & $0 \mathrm{kWh}$ & $116.1 \mathrm{kWh}$ \\
\hline$D_{9}$ & $0 \mathrm{~kW}$ & $100 \mathrm{~kW}$ & $S_{5}$ & $0 \mathrm{kWh}$ & $0 \mathrm{kWh}$ \\
\hline$D_{10}$ & $0 \mathrm{~kW}$ & $26.5 \mathrm{~kW}$ & $S_{6}$ & $0 \mathrm{~kg}$ & $25.2 \mathrm{~kg}$ \\
\hline$D_{11}$ & $0 \mathrm{~kW}$ & $26.5 \mathrm{~kW}$ & $S_{7}$ & $0 \mathrm{kWh}$ & $335.4 \mathrm{kWh}$ \\
\hline$D_{12}$ & $7.5 \mathrm{~m}^{3} / \mathrm{h}$ & $8.5 \mathrm{~m}^{3} / \mathrm{h}$ & $S_{8}$ & $0 \mathrm{kWh}$ & $20 \mathrm{kWh}$ \\
\hline- & - & - & $S_{9}$ & $0 \mathrm{~m}^{3}$ & $6 \mathrm{~m}^{3}$ \\
\hline$Q_{c h, 1}$ & $0 \mathrm{~kW}$ & $3 \mathrm{~kW}$ & $Q_{d i s, 1}$ & $0 \mathrm{~kW}$ & $3 \mathrm{~kW}$ \\
\hline$Q_{c h, 2}$ & $0 \mathrm{~kW}$ & $20.9 \mathrm{~kW}$ & $Q_{d i s, 2}$ & $0 \mathrm{~kW}$ & $20.9 \mathrm{~kW}$ \\
\hline$Q_{c h, 3}$ & $0 \mathrm{~kW}$ & $125.4 \mathrm{~kW}$ & $Q_{d i s, 3}$ & $0 \mathrm{~kW}$ & $125.4 \mathrm{~kW}$ \\
\hline$Q_{c h, 4}$ & $0 \mathrm{~kW}$ & $104.5 \mathrm{~kW}$ & $Q_{d i s, 4}$ & $0 \mathrm{~kW}$ & $104.5 \mathrm{~kW}$ \\
\hline$Q_{c h, 5}$ & $0 \mathrm{~kW}$ & $0 \mathrm{~kW}$ & $Q_{d i s, 5}$ & $0 \mathrm{~kW}$ & $0 \mathrm{~kW}$ \\
\hline$Q_{c h, 6}$ & $0 \mathrm{~kg} / \mathrm{h}$ & $51 \mathrm{~kg} / \mathrm{h}$ & $Q_{d i s, 6}$ & $0 \mathrm{~kg} / \mathrm{h}$ & $51 \mathrm{~kg} / \mathrm{h}$ \\
\hline$Q_{c h, 7}$ & $0 \mathrm{~kW}$ & $250.8 \mathrm{~kW}$ & $Q_{d i s, 7}$ & $0 \mathrm{~kW}$ & $250.8 \mathrm{~kW}$ \\
\hline$Q_{c h, 8}$ & $0 \mathrm{~kW}$ & $3 \mathrm{~kW}$ & $Q_{d i s, 8}$ & $0 \mathrm{~kW}$ & $3 \mathrm{~kW}$ \\
\hline$Q_{c h, 9}$ & $0 \mathrm{~m}^{3} / \mathrm{h}$ & $3 \mathrm{~m}^{3} / \mathrm{h}$ & $Q_{d i s, 9}$ & $0 \mathrm{~m}^{3} / \mathrm{h}$ & $3 \mathrm{~m}^{3} / \mathrm{h}$ \\
\hline
\end{tabular}
are set to infinity. However, the flows are indirectly limited by the production capacity of the conversion devices.

In contrast, devices 1-4 limits are set using weather conditions and the isotropic sky model for radiation on sloped surfaces described in [43]. In the case of photovoltaic systems, irradiance on a tilted surface multiplied by the total surface area of the PV field becomes both the upper and lower limits because there is 
no control system to adjust the irradiance received (only the electricity produced can be controlled through their maximum power point trackers, which are not connected to the SCADA system) [44]. In the case of the photovoltaic parking area, this value is scaled to a tenth of its capacity to make the analyzed situations more realistic: the Spanish self-consumption regulations limit the power of photovoltaic facilities so this arrangement adapts the values of the energy produced to those typically demanded by the industrial cluster considered. Upper limits are calculated in the same way, for both solar collector systems (the one in CIESOL [45] and the other in the desalination plant [46]) but since their control system can regulate the inlet water flow, the lower limits are set to zero.

As to conversion, degradation, charge and discharge coefficient values, static models are again used for most devices, as shown in Table 5.

Table 5: Conversion, degradation, charge and discharge coefficients

\begin{tabular}{cc|cc|cc|cc}
\hline \hline Coeff. & Value & Coeff. & Value & Coeff. & Value & Coeff. & Value \\
\hline$\eta_{D, 5}$ & 11.54 & $\eta_{l, 1}$ & 0.02 & $\eta_{c h, 1}$ & 0.7 & $\eta_{d i s, 1}$ & 0.8 \\
$\eta_{D, 6}$ & 11.54 & $\eta_{l, 2}$ & 0.06 & $\eta_{c h, 2}$ & 0.9 & $\eta_{d i s, 2}$ & 0.9 \\
$\eta_{D, 7}$ & 4.25 & $\eta_{l, 3}$ & 0.06 & $\eta_{c h, 3}$ & 0.9 & $\eta_{d i s, 3}$ & 0.9 \\
$\eta_{D, 8}$ & 1.76 & $\eta_{l, 4}$ & 0.06 & $\eta_{c h, 4}$ & 0.9 & $\eta_{d i s, 4}$ & 0.9 \\
$\eta_{D, 9}$ & 0.7 & $\eta_{l, 5}$ & 0.02 & $\eta_{c h, 5}$ & 0.7 & $\eta_{d i s, 5}$ & 0.8 \\
$\eta_{D, 10}$ & 2.9 & $\eta_{l, 6}$ & 0 & $\eta_{c h, 6}$ & 1 & $\eta_{d i s, 6}$ & 1 \\
$\eta_{D, 11}$ & 3.1 & $\eta_{l, 7}$ & 0.06 & $\eta_{c h, 7}$ & 0.9 & $\eta_{d i s, 7}$ & 0.9 \\
$\eta_{D, 12}$ & 0.32 & $\eta_{l, 8}$ & 0.02 & $\eta_{c h, 8}$ & 0.7 & $\eta_{d i s, 8}$ & 0.8 \\
- & - & $\eta_{l, 9}$ & 0 & $\eta_{c h, 9}$ & 1 & $\eta_{d i s, 9}$ & 1 \\
\hline \hline
\end{tabular}

Combustion system coefficients are determined according to each fuel lower heating value and assuming a $90 \%$ global efficiency for thermal energy, a $98 \%$ combustion efficiency and a $45 \%$ carbon content in the biomass. Both the reversible heat pump and the absorption chiller coefficients are obtained from their datasheets whereas the desalination plant conversion is obtained from [42]. For storage systems, either hypothetical values are assumed or values obtained from experimentation are included [26].

To reiterate, power conversion in PV systems is calculated using the methodology proposed in [43] (thus using the equivalent circuit for a PV generator to calculate the maximum power point current and voltage) whereas inverter performance is determined using their datasheet specifications and the models presented in [44]. Apart from this, both collector system coefficients are obtained through previously obtained models for each field $[45,46]$.

\subsubsection{Resource prices}

Firstly, the vectors $\boldsymbol{c}(k)$ and $\boldsymbol{s}(k)$ are defined through equations (19) and (20) to express the price of the resource flows represented by $\boldsymbol{I}(k)$ and $\boldsymbol{M}(k)$, where zeros refer to cost-free resources.

$$
\begin{aligned}
\boldsymbol{c}(k) & =\left[\begin{array}{llllllll}
c_{1} & c_{2} & c_{3} & 0 & c_{5} & c_{6} & 0 & c_{8}
\end{array}\right] \\
\boldsymbol{s}(k) & =\left[\begin{array}{lllllllll}
s_{1} & 0 & 0 & 0 & 0 & 0 & 0 & 0 & s_{9}
\end{array}\right]
\end{aligned}
$$

Electricity cost $c_{1}=1.21 p_{E}$ is calculated according to the local supply company tariff with super off-peak time discrimination [47], for low-voltage contracted power over $15 \mathrm{~kW}$, with winter and summer 
Table 6: Local supply company tariff prices $\left(p_{E}\right)$ [47]

\begin{tabular}{cccc}
\hline \hline Period & Price $(€ / \mathrm{kWh})$ & Winter $(\mathrm{UTC}+1)$ & Summer $(\mathrm{UTC}+2)$ \\
\hline P1 & 0.168899 & $18-22 \mathrm{~h}$ & $11-15 \mathrm{~h}$ \\
P2 & 0.093162 & $8-18 \mathrm{~h} / 22-24 \mathrm{~h}$ & $8-11 \mathrm{~h} / 15-24 \mathrm{~h}$ \\
P3 & 0.073738 & $0-8 \mathrm{~h}$ & $0-8 \mathrm{~h}$ \\
\hline \hline
\end{tabular}

corresponding to daylight saving time periods. A $21 \%$ value-added tax (VAT) is applied to prices $\left(p_{E}\right)$ presented in Table 6.

Photovoltaic energy costs $c_{2}=\eta_{1} p_{P V}$ and $c_{3}=\eta_{2} p_{P V}$ are obtained from variable charges over the 3.0A access fee [38] shown in Table 7. Since these prices $\left(p_{P V}\right)$ refer to self-consumed energy, two adjustments are performed: prices in Table 7 are multiplied by $\eta_{1}$ and $\eta_{2}$ to get, respectively, $c_{2}$ and $c_{3}$ in terms of radiant power, and prices are aggregated to $s_{1}$ in order to take into account the portion of non-self-consumed energy.

Table 7: Variable charges with the 3.0A access fee $\left(p_{P V}\right)$ [38]

\begin{tabular}{cccc}
\hline \hline Period & Price $(€ / \mathrm{kWh})$ & Winter $(\mathrm{UTC}+1)$ & Summer $(\mathrm{UTC}+2)$ \\
\hline P1 & 0.019894 & $18-22 \mathrm{~h}$ & $11-15 \mathrm{~h}$ \\
P2 & 0.013147 & $8-18 \mathrm{~h} / 22-24 \mathrm{~h}$ & $8-11 \mathrm{~h} / 15-24 \mathrm{~h}$ \\
$\mathrm{P} 3$ & 0.008459 & $0-8 \mathrm{~h}$ & $0-8 \mathrm{~h}$ \\
\hline \hline
\end{tabular}

With regard to the remaining $\boldsymbol{c}(k)$ elements, constant values are assumed based on local retailer prices: the propane cost $c_{5}$ is fixed at $1.4 € / \mathrm{kg}$ plus $21 \%$ VAT [48], the biomass cost $c_{6}$ is fixed at $0.255 € / \mathrm{kg}$ (VAT included) [49] and the water cost $c_{8}$ is fixed at $0.497 € / \mathrm{m}^{3}$ plus $10 \%$ VAT [50].

Regarding sales, electricity prices (6) from daily and intraday markets $\left(p_{E S}\right)$, expressed in $€ / \mathrm{MWh}$, are considered together with the generation fee $(0.5 € / \mathrm{MWh})$, the $7 \%$ IVPEE and the non-self-consumed energy in order to calculate $s_{1}(21)$. Water $\left(s_{9}\right)$ is considered to be sold at $90 \%$ of the purchase price; in other words, $0.447 € / \mathrm{m}^{3}$. Note that the $s_{6}$ price is zero because $M_{6}$ expresses the amount of $\mathrm{CO}_{2}$ released from storage.

$$
s_{1}=\left(0.93 p_{E S}-0.5\right) / 1000+p_{P V}
$$

\subsection{Simulation scenarios}

\subsubsection{Management strategy}

Assuming that the output vector, the weather conditions and the resource prices are known, or at least estimated with a high degree of confidence, for a period of $H$ hours, different criteria (economic, environmental etc.) can be considered to determine the operation scheduling (i.e. the values for input, charge, discharge vectors and the binary variables, which are decision variables) minimizing an objective function. In this case, the management strategy aimed at achieving the lowest operation cost is applied by solving the optimization problem stated in equation (22) (sample time $T$ in minutes and divisor of $H$ ).

In real applications, the decision variables determined this way can constitute setpoints for lower-level control loops, which adjust the operation for each device. Because of uncertainties in energy prices and demand, the decision variables must be dynamically determined and so the optimization problem is solved iteratively in order to update the setpoint values. Similar to model predictive control algorithms, a receding 
but variable horizon strategy is employed: operation scheduling is calculated by repeatedly solving the above-mentioned problem with different values of $H$, only taking into account the decision variable values of the first sample.

For simplicity's sake, only resource cost is considered, so $\boldsymbol{c}(k)$ and $\boldsymbol{s}(k)$ are row vectors containing the price of each input or sold resource in terms of energy, mass or volume. For this reason, the expression $T / 60$ appears in the equation. Self-consumption fixed charges and maintenance costs are not taken into account.

$$
\min \sum_{k=1}^{H \frac{60}{T}}(\boldsymbol{c}(k) \boldsymbol{I}(k)-\boldsymbol{s}(k) \boldsymbol{M}(k)) \frac{T}{60}
$$

s.t. the aforementioned constraints

Both the legal framework and the electricity market have been detailed in this section to justify resource pricing and formulate the problem formally. The cluster can be sorted out as self-consumption type 2, and therefore the surplus energy produced in the photovoltaic facilities can be sold through the public utility network. Thus, electricity pricing plays a fundamental role in the optimization problem since it delimits the $H$ value and determines the first element of the $s(k)$ vector. Although prices are updated four times in the daily market, only the Final Viable Daily Schedule price published before 17:00 h $($ UTC+1/UTC+2) is available for download; therefore, this time will be employed to determine the length of the optimization horizon together with the intraday session's FHS publication time (the output vector, the weather conditions and the remaining resource prices are assumed to be known for any given time period):

- From $0 \mathrm{~h}$ to $18 \mathrm{~h}$ (UTC+1/UTC+2), the operation scheduling is calculated by shortening $H$ in order to make it equal to the difference between the current time and midnight, the period when the electricity price is known.

- From $18 \mathrm{~h}$ to $24 \mathrm{~h}(\mathrm{UTC}+1 / \mathrm{UTC}+2)$, the electricity price is published for the whole of the following day, so $H$ takes a value of $24 \mathrm{~h}$.

In both cases, the vector $\boldsymbol{s}(k)$ is updated according to the prices published by OMIE concerning daily and intraday markets, as detailed below, leaving an hour-long margin to the time when prices are published. Fixing the sample time to sixty minutes, which is a reasonable choice considering that electricity prices are published on this basis, Fig. 5 represents the length of the horizon for the twenty-four iterations required to obtain the day scheduling and the updated prices.

\subsubsection{Selected experimental data}

With regard to weather conditions and demand profiles, two days are selected from the 2013-2017 period as an example of a summer (01/08/2014) and winter (31/01/2014) day. All the parameters characterizing each kind of day (the output vector, the ambient temperature, the solar radiation and the electricity price) are depicted below in Figs. 6 to 8. Since $H$ can take a value of $24 \mathrm{~h}$, the period of data corresponding to 02/08/2014 and 01/02/2014 are also included. All data were averaged over a sixty-minute period and the storage systems are supposed to be empty at the outset.

In first place, Fig. 6 consists of the electricity prices from the daily (FVDS) and intraday markets, as published by OMIE for the periods considered. Because of the horizon of each session, the prices of Session 2 overlap between 21-24 h, whereas in Sessions 3 to 6, gaps appear in the hours prior to price publication. In accordance with the strategy proposed and the sample time of sixty minutes, the prices employed in each iteration are determined as shown in Fig. 5; those employed for simulations have been shadowed in Fig. 6. 


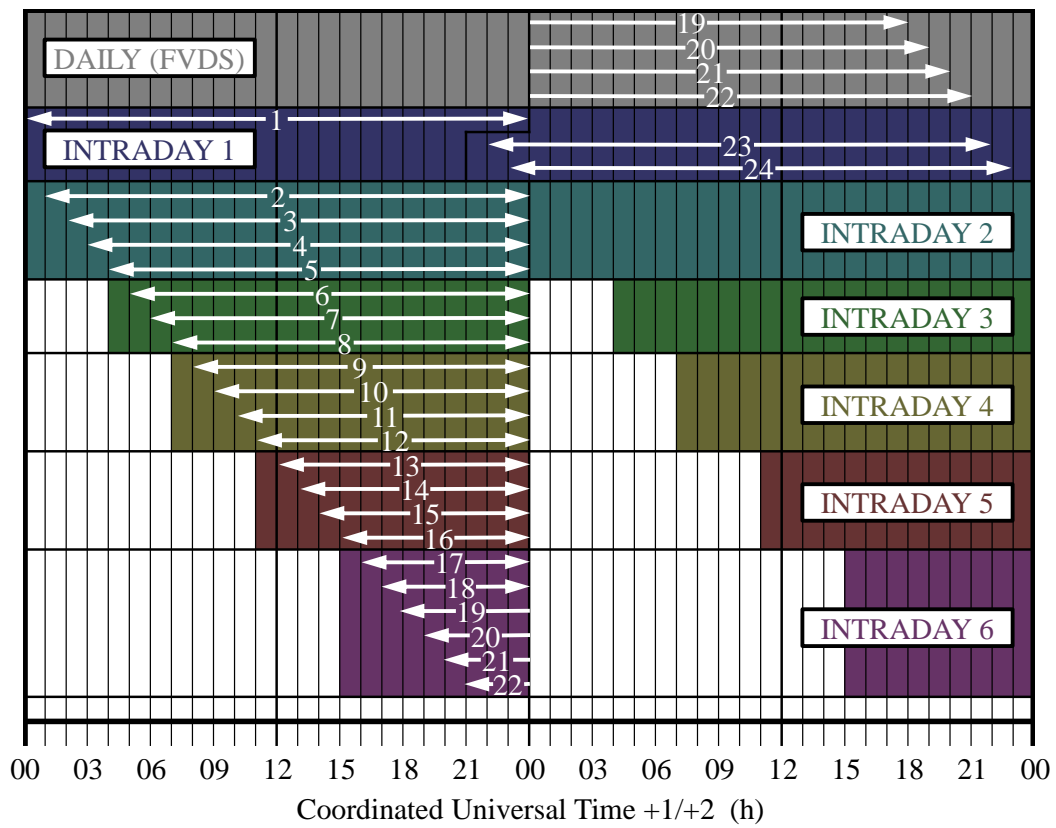

Figure 5: Optimization horizons for each iteration performed to obtain the scheduling and to update the prices in each one (numbers between arrows delimit the intervals considered). In iterations 19 to 22, prices from both the daily market and the sixth session of the intraday are employed, so the arrows are divided to indicate the prices corresponding to each one. The time axis label refers to both summer $(\mathrm{UTC}+2)$ and winter periods $(\mathrm{UTC}+1)$.

In addition, weather conditions directly affect the amount of energy produced in the solar systems: the available solar radiation is required to determine the lower and/or upper limit of certain devices and the ambient temperature is related to the performance of the same. In order to give an idea of the contrast between both days, Fig. 7 illustrates the ambient temperature together with the global, beam, and diffuse radiation in each case. As can be observed, the summer period at the latitude considered is characterized by higher temperatures for both days, oscillating between $18.4{ }^{\circ} \mathrm{C}$ and $30.4{ }^{\circ} \mathrm{C}$ versus $8.1^{\circ} \mathrm{C}$ and $21.8^{\circ} \mathrm{C}$ in the winter period. Global Horizontal Irradiance (GHI), Direct Normal Irradiance (DNI) intensity and insolation in the first case also surpass those in the second whereas these data, together with the Diffuse Horizontal Irradiance (DHI) profiles, reflect the presence of cloudiness on 31/01/2014 and 01/02/2014 (cloudiness increases the amount of DHI and diminishes the DNI).

Indirectly, the demand profiles are also influenced by the weather conditions so it is important to depict the output resources required for all the facilities, as presented in Fig. 8, to understand the results. On the one hand, Fig. 8(a) contains the electric power consumed in CIESOL and the greenhouse and also the thermal power required by the building. The electricity profiles are quite similar since, in both periods, a base power of around $65 \mathrm{~kW}$ is demanded; although some peaks can be identified coinciding with the time activities are carried out in the facilities. Thermal power demand is strongly related to the workday and the season of the year: in summer the workday is shorter and there is only cooling demand, which is concentrated during the morning (from 8 to $15 \mathrm{~h}$ on 01/08/2014), whereas in winter the workday usually last beyond $18 \mathrm{~h}$ and only heating is required. The 01/02/2014 date corresponds to a non-working day (Saturday) and therefore the heating profile is nil.

On the other hand, Fig. 8(b) mainly represents the greenhouse's resource demand. Heating and $\mathrm{CO}_{2}$ usually constitute opposite profiles since the former is needed at night, especially when the ambient temper- 


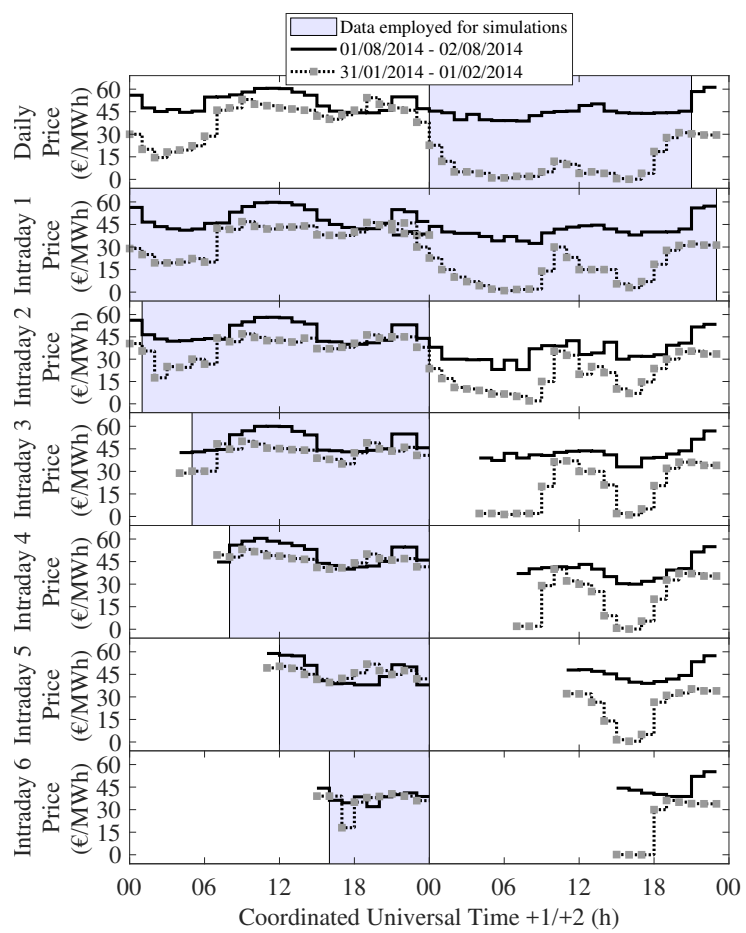

Figure 6: Electricity prices [34] for the scenarios simulated. The shadowed areas indicate the data employed when the strategy proposed is applied (see Fig. 5). In general, the energy is more expensive on the summer days (01/08/2014-02/08/2014) versus the winter days (31/01/2014-01/02/2014). The time axis label refers to both summer (UTC+2) and winter periods (UTC+1).

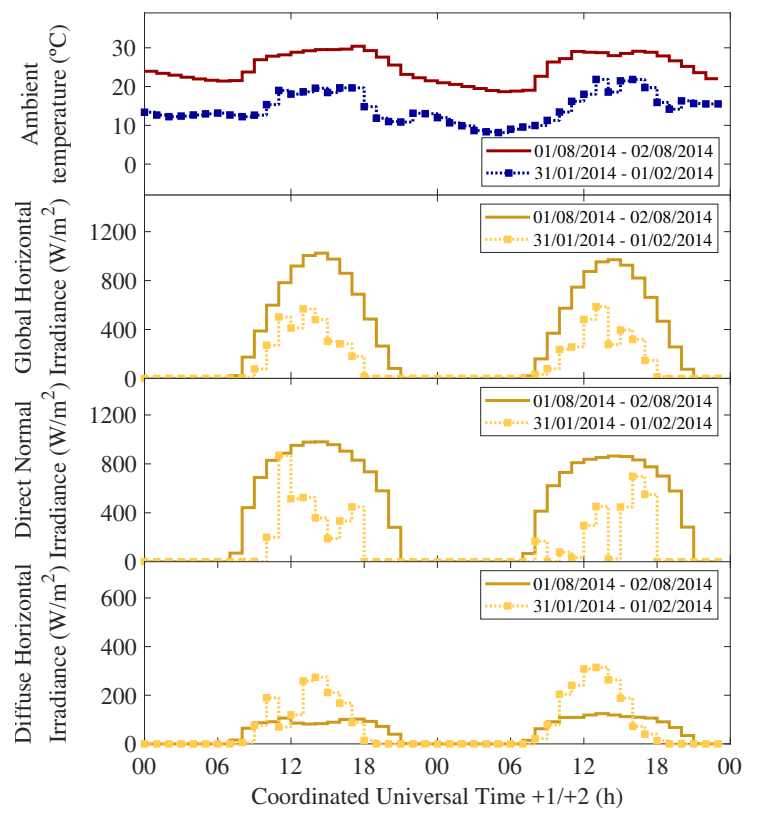

Figure 7: Weather conditions for the scenarios simulated. The summer period (01/08/2014-02/08/2014) corresponds to higher average levels of temperature and radiation versus the winter period (31/01/2014-01/02/2014). The time axis label refers to both summer (UTC+2) and winter periods (UTC+1). 


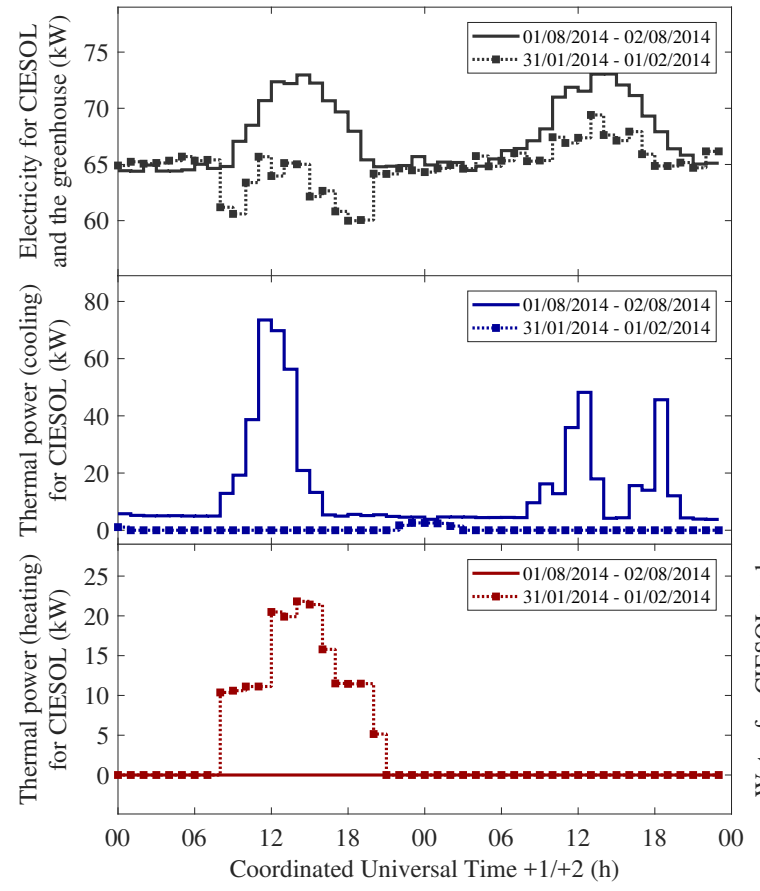

(a)

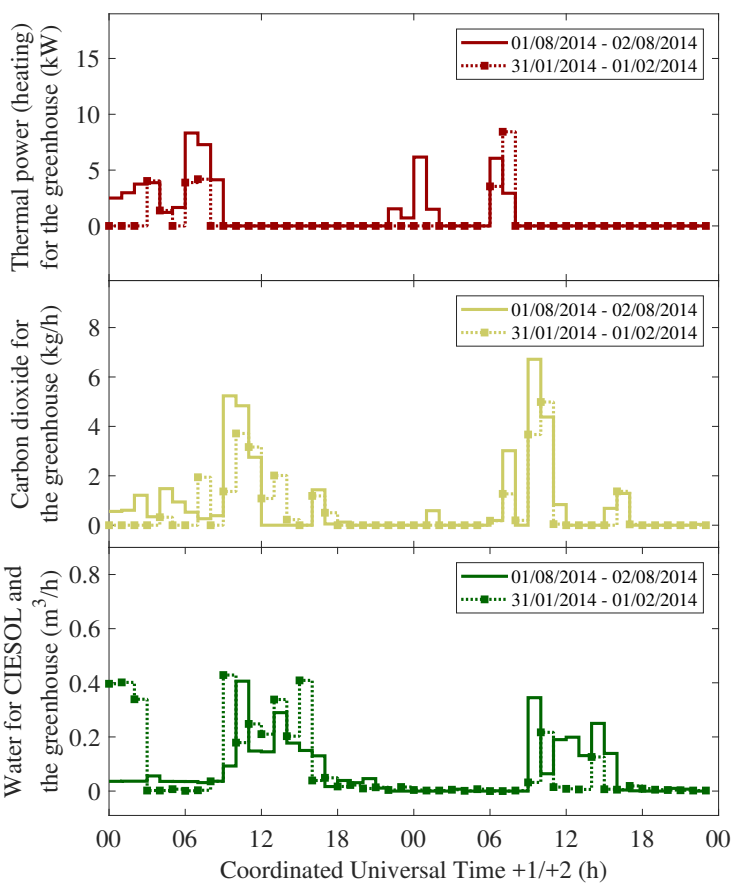

(b)

Figure 8: Demands for the scenarios simulated. (a): electricity for $O_{1}$ (top), heating for $O_{2}$ (middle) and cooling for $O_{3}$ (bottom). (b): heating for $O_{4}$ (top), $\mathrm{CO}_{2}$ for $O_{6}$ (middle), and water for $O_{9}$ (bottom). The outputs attached to binary variables are not included since they are not known beforehand. The time axis label refers to both summer (UTC+2) and winter periods (UTC+1).

ature is lower (usually in winter) while the latter is related to photosynthetic activity, which only occurs in the presence of radiation (the availability of which is higher in summer) during the day. Fig. 8(b) illustrates these facts, since the thermal power demanded is higher on 31/01/2014 and on 01/02/2014; as does the $\mathrm{CO}_{2}$ on 01/08/2014 and on 02/08/2014. With regard to water requirements, these increase during the workday, with peaks in periods of greenhouse irrigation, and with no significant differences between both scenarios.

\subsection{Resource scheduling results}

The problem addressed is solved by running MATLAB ${ }^{\circledR}$ solver intlinprog [51] iteratively on an Intel ${ }^{\circledR}$ Core $^{\mathrm{TM}}$ i7-6700K 4GHz CPU, taking less than two minutes for each simulated scenario. Results for 01/08/2014 are shown in Fig. 9 and on 31/01/2014 in Fig. 10, employing colors according to each kind of resource as in Fig. 4. Each figure contains the hourly demand profiles (outputs), plotted with a thick line, and the market sales profile $\left(M_{o}\right)$, stacked over the latter with a thin line; both are scaled to the left axis and expressed in terms of power or flow. The dashed line, scaled to the right axis, represent the evolution of the storage systems, corresponding to each output $\left(S_{o}\right)$, in terms of energy, mass or volume. In each plot, the right axis upper limit corresponds to the storage maximum capacity (except for $S_{5}$ ). Colored stacked bars (scaled to the left axis) indicate inputs for which demands are met $\left(I_{i}\right)$; therefore, when they are over the demand and sales profiles, the storage systems are charged (so the dashed line has a positive slope) whereas they are discharged when under them. Because of the degradation assumed in certain stored resources (see Table 5), in some cases the storage profile has a negative slope, similar to a discharge, even when the demand and sales profiles are met (see for example $S_{1}$ in Fig. 9(a) between $18 \mathrm{~h}$ and $24 \mathrm{~h}$ or $S_{2}$ in Fig. 10(a) 
between $12 \mathrm{~h}$ and $22 \mathrm{~h}$ ).

Fig. 9(a) and Fig. 10(a) combine the results obtained for the thermal power demanded by CIESOL and the electricity that it and the greenhouse need. Heating demand during the summer day is nil $\left(\mathrm{O}_{3}\right.$ in Fig. 9(a)) and this is almost the same with the cooling demand on the winter day $\left(\mathrm{O}_{2}\right.$ in Fig. 10(a)). The solar energy value is manifested in the remaining plots since the demand during the morning and the afternoon is covered by photovoltaic (see $I_{2}$ and $I_{3}$ ) or solar thermal power $\left(I_{4}\right)$. This is because solar alternatives are cheaper than purchasing electricity $\left(I_{1}\right)$, providing that sufficient radiation is available. A key difference between the summer and the winter day is that the electricity storage system $\left(S_{1}\right)$ is not completely empty at day's end in summer. This is justified because the prices for the following day (see shadowed Daily Prices in Fig. 6) make it profitable to store energy in the first case (01/08/2014) but not in the second (31/01/2014), when prices fall by around $30 € / \mathrm{MWh}$. The thermal storage system $\left(S_{2}\right.$ and $\left.S_{3}\right)$ variations experience consistent behavior: accumulating energy during the sun hours to utilize it during the evening and at night, instead of using electricity. The only exception to this is the biomass boiler $\left(I_{6}\right)$ working during the night, at $0 \mathrm{~h}$ on 01/08/2014 and at $3 \mathrm{~h}$ on 31/01/2014, in order to take advantage of both the $\mathrm{CO}_{2}$ and the heat demanded (see $O_{4}$ and $O_{6}$ in Fig. 9(b) and Fig. 10(b) at those times). With regard to electricity sales $\left(M_{1}\right)$, these are clearly noticeable on 01/08/2014 during the afternoon and, to a lesser extent, on 31/01/2014 at 13 h.

Fig. 9(b) and Fig. 10(b) contain the results related to the $\mathrm{CO}_{2}$ and thermal power consumption of the greenhouse. Note that the colored stacked bars corresponding to the inputs which meet the demands in each figure are presented at the same time ( $0 \mathrm{~h}$ on $01 / 08 / 2014$ and $3 \mathrm{~h}$ on $31 / 01 / 2014)$. The explanations for the scheduling observed are as follows: the only source to produce carbon dioxide is the biomass boiler $\left(I_{6}\right)$ but, on the one hand, its input mass flow is limited to a minimum of $15 \mathrm{~kg} / \mathrm{h}$ (see Table 4) and, on the other, the cost of storing $\mathrm{CO}_{2}$ increases with the number of times that the compressor activates $\left(O_{5}\right)$. Therefore, as soon as the greenhouse requires this gas enrichment $\left(O_{6}\right)$, the reasonable decision is to produce all the $\mathrm{CO}_{2}$ required for the whole day in a single step so as to avoid wasting electricity with the compressor $\left(\mathrm{O}_{5}\right)$. Given that more $\mathrm{CO}_{2}$ than required is produced because of the boiler's input lower limit, a portion is released $\left(M_{6}\right)$ in both cases. Additionally, the thermal energy produced is stored $\left(S_{2}, S_{3}, S_{4}\right)$ or employed to supply other demands $\left(\mathrm{O}_{2}, \mathrm{O}_{3}, \mathrm{O}_{4}\right)$, as shown in Fig. 9(a) at the middle and bottom, and in Fig. 9(b) at the top. Since the carbon dioxide is required $\left(\mathrm{O}_{6}\right)$ for the first time during the night in both cases, solar energy sources $\left(I_{2}, I_{3}\right)$ cannot be employed to supply electricity to the compressor $\left(O_{5}\right)$. The greenhouse thermal demand $\left(\mathrm{O}_{4}\right)$ is almost entirely covered with the heat produced by the boiler, except at $23 \mathrm{~h}$ on 01/08/2014 when the propane heater actuates as a support supply $\left(I_{5}\right)$.

Fig. 9(c) and Fig. 10(c) include the scheduling for the water and the desalination plant demands. The main differences between both days is that powering the desalination plant $\left(O_{7}, O_{8}\right)$ to produce water on 31/01/2014 was not worthwhile (Fig. 10(c)), even though this is not necessarily the general case in winter, since the energy from the sun $\left(I_{2}, I_{3}, I_{4}\right)$ is not enough to cover the requirements of the whole energy hub (using propane and acquiring electricity increases the cost) and buying water instead $\left(I_{8}\right)$ is more economical. Fig. 9(c) illustrates the opposite situation: the abundance of radiation allows seawater to be distilled at a lower cost. In this case, the amount of water produced $\left(I_{7}\right)$ is more than needed $\left(O_{9}\right)$ in order to sell the excess through the public network $\left(M_{9}\right)$ or to store it $\left(S_{9}\right)$ for the following day (when it would likewise be sold or consumed). The figure also shows how the desalination plant power demand $\left(\mathrm{O}_{7}\right.$, $O_{8}$ ) corresponds to the periods when water is produced $\left(I_{7}\right)$. Although in this case the demands are met through the solar production facilities $\left(I_{2}, I_{3}, I_{4}\right)$, the support of the power grid $\left(I_{1}\right)$ and the propane boiler $\left(I_{5}\right)$ could be necessary under certain circumstances to supply water profitably (for example complementing the photovoltaic and solar thermal production). 


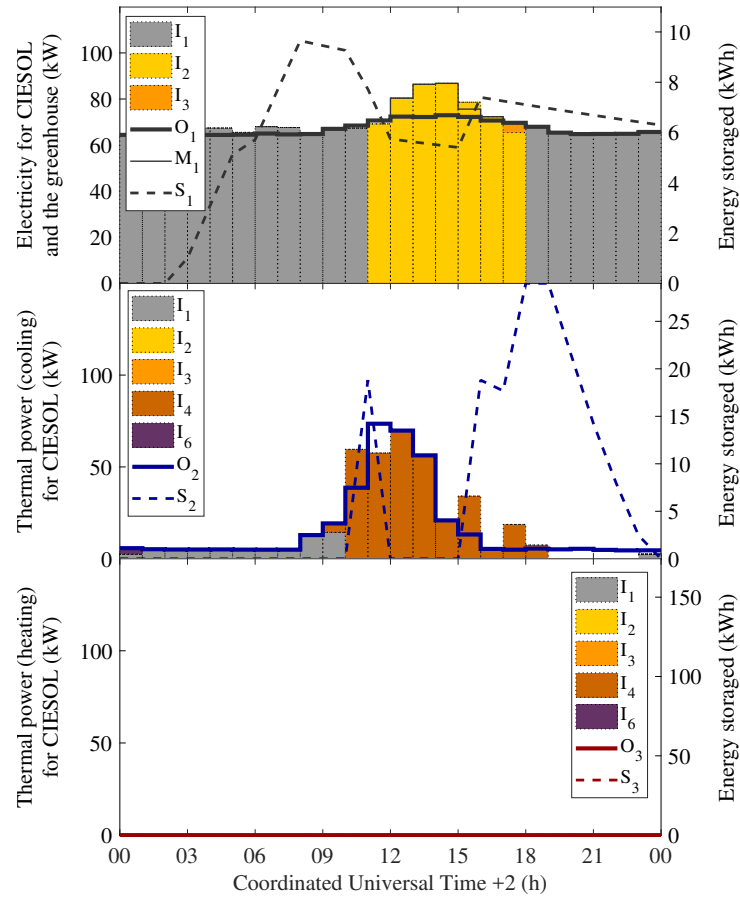

(a)

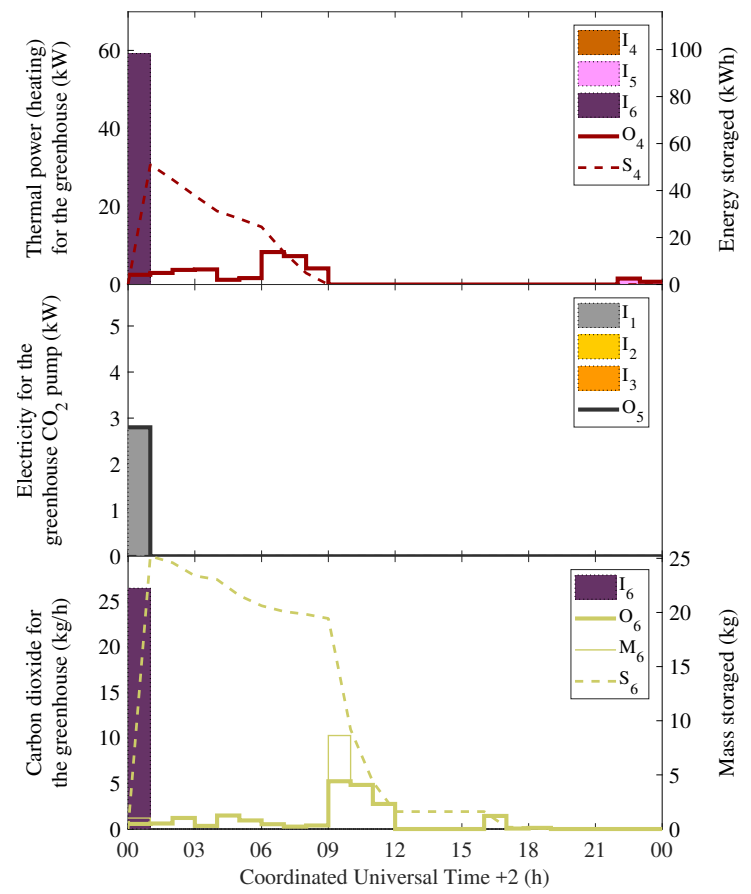

(b)

Figure 9: Simulation results on 01/08/2014. (a), (b), and (c) contain the scheduling for each output $\left(O_{o}\right)$ of the case study energy hub, sorted by number and including the evolution of each storage system $\left(S_{o}\right)$, the inputs through which the demand is met $\left(I_{i}\right)$, and the resources sold $\left(M_{o}\right)$.

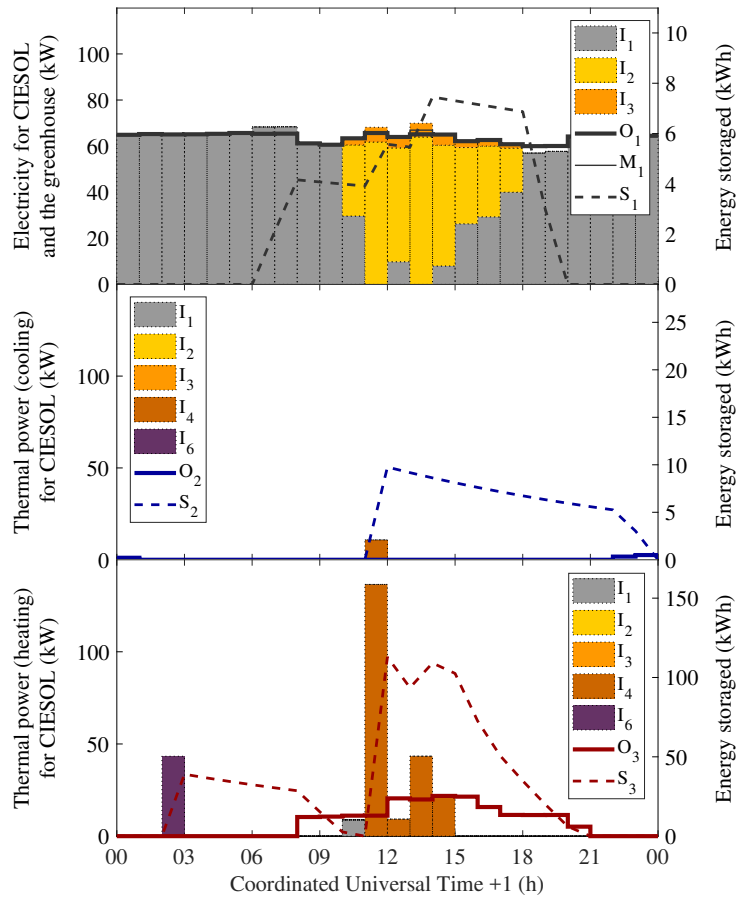

(a)

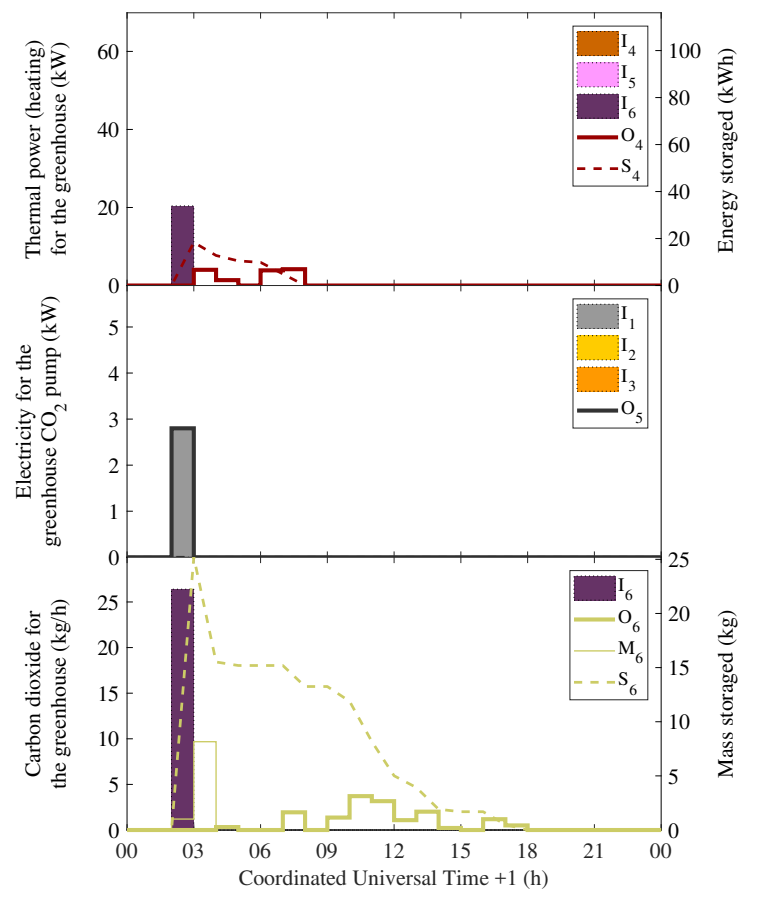

(b)

Figure 10: Simulation results on 31/01/2014. (a), (b), and (c) contain the scheduling for each output $\left(O_{o}\right)$ of the case study energy hub, sorted by number and including the evolution of each storage system $\left(S_{o}\right)$, the inputs through which the demand is met $\left(I_{i}\right)$, and the resources sold $\left(M_{o}\right)$. 


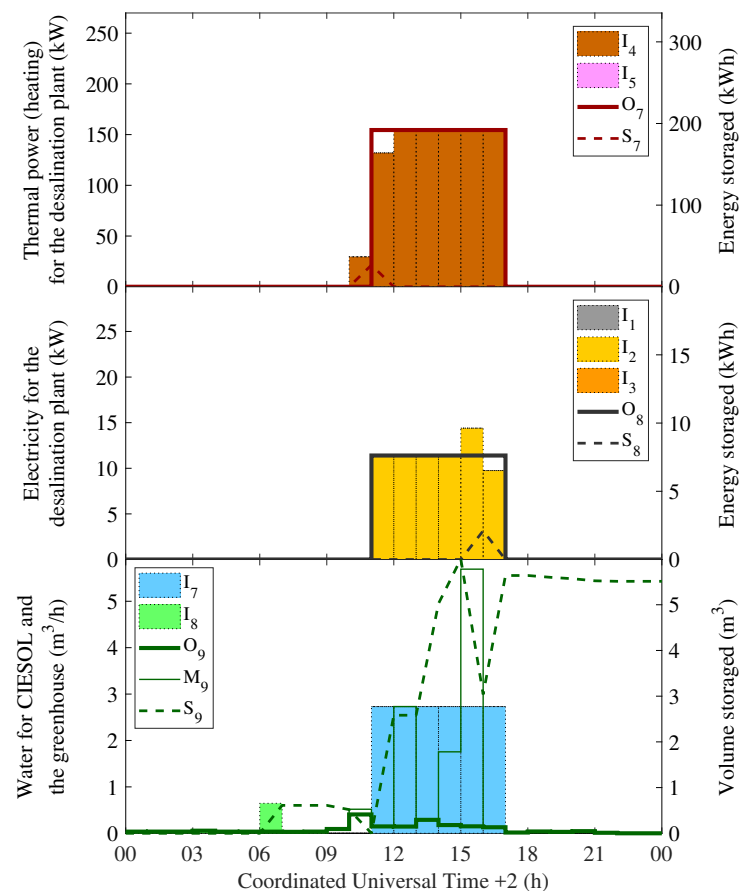

(c)

Figure 9 (Cont.): Simulation results on 01/08/2014. (a), (b), and (c) contain the scheduling for each output $\left(O_{o}\right)$ of the case study energy hub, sorted by number and including the evolution of each storage system $\left(S_{o}\right)$, the inputs through which the demand is met $\left(I_{i}\right)$, and the resources sold $\left(M_{o}\right)$.

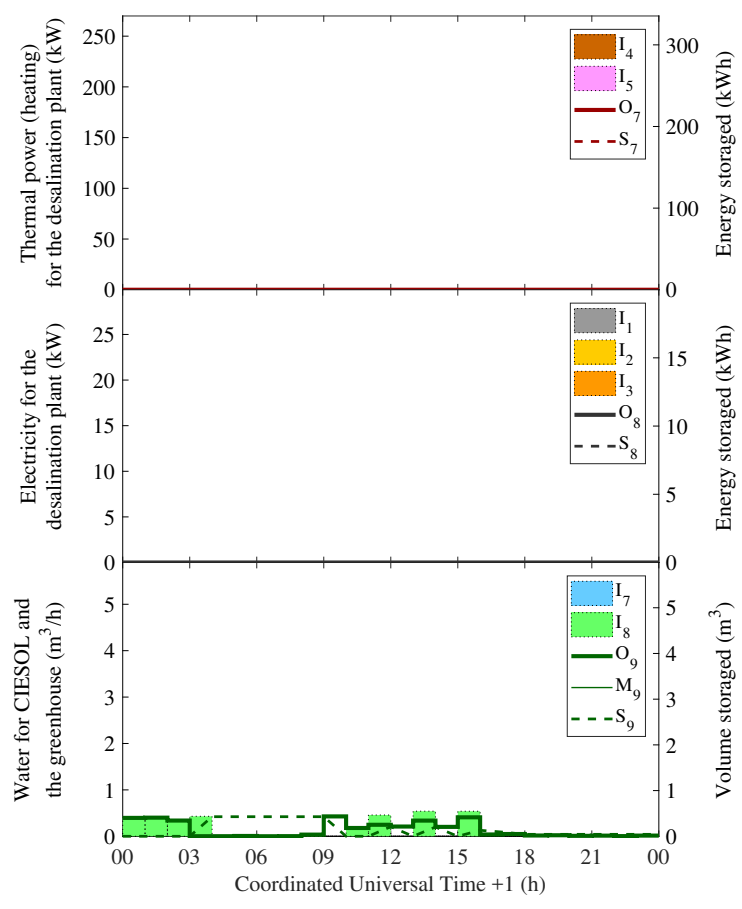

(c)

Figure 10 (Cont.): Simulation results on 31/01/2014. (a), (b), and (c) contain the scheduling for each output $\left(O_{o}\right)$ of the case study energy hub, sorted by number and including the evolution of each storage system $\left(S_{o}\right)$, the inputs through which the demand is met $\left(I_{i}\right)$, and the resources sold $\left(M_{o}\right)$.

In addition, all these results are summarized in Table 8 in terms of demanded/supplied energy, mass or volume for vectors $\boldsymbol{I}, \boldsymbol{O}$ and $\boldsymbol{M}$ over the simulated days. Also, the total cost of importing (positive values) or selling resources (negative values) are included, according to vectors $c$ and $s$. Although demand differs between the summer and the winter day, especially that related to thermal power, in both cases the total operation cost is quite similar: less than a $3 €$ difference. Higher demands on 01/08/2014 were compensated for by electricity and water sales through the public utility networks.

\section{Conclusions}

A holistic proposal for resource management such as the energy hub concept presented in this research can be a suitable instrument for resource scheduling problems. The coherent results obtained prove that the approach adopted is appropriate even when the scheduling depends on mutually exclusive decisions (for example, resolving when a device must actuate or not) and show the validity of the new elements introduced in the energy hub framework. Although for the purpose of this paper only a few cases have been presented, the programming has been carefully performed in a way that not only different scenarios can be considered but also different energy hubs, simply by defining their structures (inputs, outputs, devices and paths) in a straightforward way.

The proposed management approach helps one to augment the accuracy of the process represented without increasing computational complexity; this is achieved by defining the path vector rather than including 
Table 8: Input, output and market total demand/supply and costs

\begin{tabular}{ccccc}
\hline \hline & \multicolumn{2}{c}{ Summer day } & \multicolumn{2}{c}{ Winter day } \\
Variable & Accumulated & Cost & Accumulated & Cost \\
\hline$I_{1}$ & $1150.28 \mathrm{kWh}$ & $116.81 €$ & $1171.32 \mathrm{kWh}$ & $141.82 €$ \\
$I_{2}$ & $5102.92 \mathrm{kWh}$ & $60.73 €$ & $2615.97 \mathrm{kWh}$ & $22.89 €$ \\
$I_{3}$ & $39.91 \mathrm{kWh}$ & $0.20 €$ & $262.63 \mathrm{kWh}$ & $2.18 €$ \\
$I_{4}$ & $3189.96 \mathrm{kWh}$ & $0 €$ & $606.42 \mathrm{kWh}$ & $0 €$ \\
$I_{5}$ & $0.19 \mathrm{~kg}$ & $0.33 €$ & $0 \mathrm{~kg}$ & $0 €$ \\
$I_{6}$ & $15 \mathrm{~kg}$ & $3.83 €$ & $15 \mathrm{~kg}$ & $3.83 €$ \\
$I_{7}$ & $51 \mathrm{~m}^{3}$ & $0 €$ & $0 \mathrm{~m}^{3}$ & $0 €$ \\
$I_{8}$ & $0.97 \mathrm{~m}^{3}$ & $0.53 €$ & $3.42 \mathrm{~m}^{3}$ & $1.87 €$ \\
\hline$O_{1}$ & $1611.58 \mathrm{kWh}$ & - & $1530.25 \mathrm{kWh}$ & - \\
$O_{2}$ & $386.96 \mathrm{kWh}$ & - & $5.37 \mathrm{kWh}$ & - \\
$O_{3}$ & $0 \mathrm{kWh}$ & - & $182.24 \mathrm{kWh}$ & - \\
$O_{4}$ & $37.93 \mathrm{kWh}$ & - & $13.48 \mathrm{kWh}$ & - \\
$O_{5}$ & $2.8 \mathrm{kWh}$ & - & $2.8 \mathrm{kWh}$ & - \\
$O_{6}$ & $20.74 \mathrm{~kg}$ & - & $15.52 \mathrm{~kg}$ & - \\
$O_{7}$ & $927.00 \mathrm{kWh}$ & - & $0 \mathrm{kWh}$ & - \\
$O_{8}$ & $68.4 \mathrm{kWh}$ & - & $0 \mathrm{kWh}$ & - \\
$O_{9}$ & $2.02 \mathrm{~m}^{3}$ & - & $3.37 \mathrm{~m}^{3}$ & - \\
\hline$M_{1}$ & $41.32 \mathrm{kWh}$ & $-2.80 €$ & $1.81 \mathrm{kWh}$ & $-0.11 €$ \\
$M_{6}$ & $5.65 \mathrm{~kg}$ & $0 €$ & $10.88 \mathrm{~kg}$ & $0 €$ \\
$M_{9}$ & $9.82 \mathrm{~m}$ & $-4.39 €$ & $0 \mathrm{~m}^{3}$ & $0 €$ \\
\hline Total & - & $175.23 €$ & - & $172.48 €$ \\
\hline \hline
\end{tabular}

a decision variable for each branch [11] between devices or between them and the input or output nodes. The computation times required for solving the scheduling problem allow one to increase the model complexity yet still make it applicable in real-time management. The choice of the receding horizon length, for instance, is one of the main computation time determinants and increasing it could improve the results obtained. However, this requires the development of electricity price estimators in addition to demand models.

In terms of future work, more in-depth studies will be performed to improve the accuracy of some parameters and to deal with their uncertainty (demand profiles, conversion factors, resource prices etc.) as well as to develop the above-mentioned models and estimators. Interactions between multiple energy hubs is another current line of research, as presented in some papers [52]. Furthermore, by making the binary variables correspond to inputs $\left(\delta_{I, i}\right)$ and device $\left(\delta_{D, d}\right)$ integer values, together with a suitable selection of upper and lower limits, devices operating at partial load could be represented - consequently, performing a comparison with stepwise approximation [10] might prove to be an interesting analysis. Another issue is the management strategy employed since it is formulated according to the self-consumption legal framework. Alternatives based on the inclusion of the energy hub as an electricity market agent could be assessed to find out the most economical scenario. Nevertheless, the current approach is still viable for a large number of prosumers who might benefit from the self-consumption law. 


\section{Acknowledgements}

This work has been funded by the National R+D+i Plan Projects DPI2014-56364-C2-1-R and DPI201785007-R of the Spanish Ministry of Economy, Industry and Competitiveness as well as by ERDF funds.

\section{Appendix A.}

Since $C_{i}, C$ and $C_{d}$ (referred to inputs) are sparse matrices, their non-zero elements are defined in this section in Tables A.9, A.11 and A.10, as follows.

Table A.9: Matrix $\boldsymbol{C}_{\boldsymbol{i}}[8 \times 30]$ elements

\begin{tabular}{ccc|ccc|ccc}
\hline \hline Row & Col. & Value & Row & Col. & Value & Row & Col. & Value \\
\hline 1 & 1 & 1 & 1 & 2 & 1 & 1 & 3 & 1 \\
1 & 4 & 1 & 1 & 5 & 1 & 2 & 6 & 1 \\
2 & 7 & 1 & 2 & 8 & 1 & 2 & 9 & 1 \\
2 & 10 & 1 & 3 & 11 & 1 & 3 & 12 & 1 \\
3 & 13 & 1 & 3 & 14 & 1 & 3 & 15 & 1 \\
4 & 16 & 1 & 4 & 17 & 1 & 4 & 18 & 1 \\
4 & 19 & 1 & 4 & 20 & 1 & 4 & 21 & 1 \\
4 & 22 & 1 & 5 & 23 & 1 & 5 & 24 & 1 \\
6 & 25 & 1 & 6 & 26 & 1 & 6 & 27 & 1 \\
7 & 29 & 1 & 8 & 30 & 1 & & & \\
\hline \hline
\end{tabular}

Table A.10: Matrix $\boldsymbol{C}_{\boldsymbol{d}}[12 \times 30]$ elements

\begin{tabular}{ccc|ccc}
\hline \hline Row & Col. & Value & Row & Col. & Value \\
\hline 1 & 6 & 1 & 1 & 7 & 1 \\
1 & 8 & 1 & 1 & 9 & 1 \\
1 & 10 & 1 & 2 & 11 & 1 \\
2 & 12 & 1 & 2 & 13 & 1 \\
2 & 14 & 1 & 2 & 15 & 1 \\
3 & 16 & 1 & 3 & 17 & 1 \\
3 & 18 & 1 & 4 & 19 & 1 \\
4 & 20 & 1 & 4 & 21 & 1 \\
4 & 22 & 1 & 5 & 23 & 1 \\
6 & 24 & 1 & 7 & 25 & 1 \\
7 & 26 & 1 & 7 & 27 & 1 \\
8 & 28 & 1 & 9 & 16 & $\delta_{D, 3}$ \\
9 & 19 & $\delta_{D, 4}$ & 9 & 25 & $\delta_{D, 7}$ \\
10 & 2 & 1 & 10 & 7 & $\delta_{D, 1}$ \\
10 & 12 & $\delta_{D, 2}$ & 11 & 3 & 1 \\
11 & 8 & $\delta_{D, 1}$ & 11 & 13 & $\delta_{D, 2}$ \\
12 & 29 & 1 & & & \\
\hline \hline
\end{tabular}

Table A.11: Matrix $\boldsymbol{C}[9 \times 30]$ elements

\begin{tabular}{ccc|ccc}
\hline \hline Row & Col. & Value & Row & Col. & Value \\
\hline 1 & 1 & 1 & 1 & 6 & $\delta_{D, 1}$ \\
1 & 11 & $\delta_{D, 2}$ & 2 & 2 & $\delta_{D, 10}$ \\
2 & 7 & $\delta_{D, 1} \delta_{D, 10}$ & 2 & 12 & $\delta_{D, 2} \delta_{D, 1}$ \\
2 & 16 & $\delta_{D, 3} \delta_{D, 9}$ & 2 & 19 & $\delta_{D, 4} \delta_{D, 9}$ \\
2 & 25 & $\delta_{D, 7} \delta_{D, 9}$ & 3 & 3 & $\delta_{D, 11}$ \\
3 & 8 & $\delta_{D, 1} \delta_{D, 11}$ & 3 & 13 & $\delta_{D, 1} \delta_{D, 11}$ \\
3 & 17 & $\delta_{D, 3}$ & 3 & 20 & $\delta_{D, 4}$ \\
3 & 26 & $\delta_{D, 7}$ & 4 & 18 & $\delta_{D, 3}$ \\
4 & 21 & $\delta_{D, 4}$ & 4 & 24 & $\delta_{D, 6}$ \\
4 & 27 & $\delta_{D, 7}$ & 5 & 5 & 1 \\
5 & 10 & $\delta_{D, 1}$ & 5 & 15 & $\delta_{D, 2}$ \\
6 & 28 & $\delta_{D, 8}$ & 7 & 22 & $\delta_{D, 4}$ \\
7 & 23 & $\delta_{D, 5}$ & 8 & 4 & 1 \\
8 & 9 & $\delta_{D, 1}$ & 8 & 14 & $\delta_{D, 2}$ \\
9 & 29 & $\delta_{D, 12}$ & 9 & 30 & 1 \\
\hline \hline
\end{tabular}




\section{References}

[1] A. Ehsan, Q. Yang, Optimal integration and planning of renewable distributed generation in the power distribution networks: A review of analytical techniques, Appl. Energy 210 (2018) 44-59.

[2] Y. Jiang, J. Xu, Y. Sun, C. Wei, J. Wang, S. Liao, D. Ke, X. Li, J. Yang, X. Peng, Coordinated operation of gas-electricity integrated distribution system with multi-cchp and distributed renewable energy sources, Appl. Energy 211 (2018) 237-248.

[3] C. D. Korkas, S. Baldi, I. Michailidis, E. B. Kosmatopoulos, Occupancy-based demand response and thermal comfort optimization in microgrids with renewable energy sources and energy storage, Appl. Energy 163 (2016) 93-104.

[4] G. Chicco, P. Mancarella, Distributed multi-generation: A comprehensive view, Renew. Sustain. Energy Rev. 13 (3) (2009) 535-551.

[5] P. Mancarella, MES (multi-energy systems): An overview of concepts and evaluation models, Energy 65 (2014) 1-17.

[6] J. Wang, H. Zhong, Z. Ma, Q. Xia, C. Kang, Review and prospect of integrated demand response in the multi-energy system, Appl. Energy 202 (2017) 772-782.

[7] M. Geidl, G. Koeppel, P. Favre-Perrod, B. Klöckl, G. Andersson, K. Fröhlich, Energy hubs for the future, IEEE Power Energy Mag. 5 (1) (2007) 24-30.

[8] M. Geidl, G. Andersson, Optimal power flow of multiple energy carriers, IEEE Trans. Power Syst. 22 (1) (2007) 145-155.

[9] A. Parisio, C. Del Vecchio, A. Vaccaro, A robust optimization approach to energy hub management, Int. J. Electr. Power Energy Syst. 42 (1) (2012) 98-104.

[10] R. Evins, K. Orehounig, V. Dorer, J. Carmeliet, New formulations of the 'energy hub' model to address operational constraints, Energy 73 (2014) 387-398.

[11] Y. Wang, J. Cheng, N. Zhang, C. Kang, Automatic and linearized modeling of energy hub and its flexibility analysis, Appl. Energy 211 (2018) 705-714.

[12] D. Setlhaolo, S. Sichilalu, J. Zhang, Residential load management in an energy hub with heat pump water heater, Appl. Energy 208 (2017) 551-560.

[13] C. Hernández-Hernández, F. Rodríguez, J. C. Moreno, P. R. da Costa Mendes, J. E. Normey-Rico, J. L. Guzmán, The comparison study of short-term prediction methods to enhance the model predictive controller applied to microgrid energy management, Energies 10 (7) (2017) 884.

[14] P. R. Mendes, L. V. Isorna, C. Bordons, J. E. Normey-Rico, Energy management of an experimental microgrid coupled to a V2G system, J. Power Sources 327 (2016) 702-713.

[15] S. D. Beigvand, H. Abdi, M. La Scala, A general model for energy hub economic dispatch, Appl. Energy 190 (2017) 10901111.

[16] P. Gabrielli, M. Gazzani, E. Martelli, M. Mazzotti, Optimal design of multi-energy systems with seasonal storage, Appl. Energy 219 (2018) 408-424.

[17] Y. Wang, N. Zhang, Z. Zhuo, C. Kang, D. Kirschen, Mixed-integer linear programming-based optimal configuration planning for energy hub: Starting from scratch, Appl. Energy 210 (2018) 1141-1150.

[18] M. Mohammadi, Y. Noorollahi, B. Mohammadi-Ivatloo, H. Yousefi, Energy hub: From a model to a concept - A review, Renew. Sustain. Energy Rev. 80 (2017) 1512-1527.

[19] J. Vasconcelos, Survey of regulatory and technological developments concerning smart metering in the European Union electricity market, European Union Institute - Robert Schuman Centre for Advanced Studies (Policy Papers 2008/01).

[20] C. Bordons, F. García-Torres, L. Valverde, Optimal energy management for renewable energy microgrids, Rev. Iberoam. Automática e Informática Ind. RIAI 12 (2) (2015) 117-132.

[21] Spanish Ministry of Industry, Energy and Tourism, Royal Decree 900/2015, of 9th October, regulating administrative, technical and economic conditions on modalities of electricity supply and generation with self-consumption, [Online]. Available: https://www.boe.es/boe/dias/2015/10/10/pdfs/BOE-A-2015-10927.pdf, Accessed on: Mar. 14, 2018.

[22] W. Elsner, M. Wysocki, P. Niegodajew, R. Borecki, Experimental and economic study of small-scale chp installation equipped with downdraft gasifier and internal combustion engine, Appl. Energy 202 (2017) 213-227.

[23] G. Merei, J. Moshövel, D. Magnor, D. U. Sauer, Optimization of self-consumption and techno-economic analysis of pvbattery systems in commercial applications, Appl. Energy 168 (2016) 171-178.

[24] R. Luthander, J. Widén, D. Nilsson, J. Palm, Photovoltaic self-consumption in buildings: A review, Appl. Energy 142 (2015) $80-94$.

[25] V. Bertsch, J. Geldermann, T. Lühn, What drives the profitability of household pv investments, self-consumption and selfsufficiency?, Appl. Energy 204 (2017) 1-15.

[26] J. A. Sánchez-Molina, J. V. Reinoso, F. G. Acién, F. Rodríguez, J. C. López, Development of a biomass-based system for nocturnal temperature and diurnal $\mathrm{CO}_{2}$ concentration control in greenhouses, Biomass and Bioenergy 67 (2014) 60-71.

[27] M. Geidl, Integrated modeling and optimization of multi-carrier energy systems, Ph.D. thesis, Power Systems Laboratory, ETH Zurich, Zurich, Switzerland (2007). 
[28] Automatic, Robotics and Mechatronics Research Group (ARM-TEP197), ENERPRO project, [Online]. Available: http: //www2.ual.es/enerpro/, Accessed on: Mar. 14, 2018.

[29] J. Ramos-Teodoro, Energy management of a heterogeneous production system under the energy hub paradigm, Master's thesis, Department of Systems Engineering and Automation, University Carlos III of Madrid, Madrid, Spain, [In Spanish] (Jul. 2017).

[30] S. Rosiek, F. J. Batlles, Renewable energy solutions for building cooling, heating and power system installed in an institutional building: Case study in southern Spain, Renew. Sustain. Energy Rev. 26 (2013) 147-168.

[31] M. M. Castilla, J. D. Álvarez, F. Rodríguez, M. Berenguel, Comfort Control in Buildings, Springer, 2014.

[32] J. A. Sánchez-Molina, F. Rodríguez, J. L. Guzmán, M. R. Arahal, Virtual sensors for designing irrigation controllers in greenhouses, Sensors 12 (11) (2012) 15244-15266.

[33] D. C. Alarcón Padilla, J. Blanco Gálvez, L. García Rodríguez, W. Gernjak, S. Malato Rodríguez, First experimental results of a new hybrid solar/gas multi-effect distillation system: the AQUASOL project, Desalination 220 (1-3) (2008) 619-625.

[34] OMI-Polo Español S.A. (OMIE), Files access, [Online]. Available: http://www.omie.es/aplicaciones/datosftp/datosftp.jsp, Accessed on: Mar. 14, 2018.

[35] J. Ramos-Teodoro, J. D. Álvarez, F. Rodríguez, M. Berenguel, Economic management of energy hubs with heterogeneous resources through MINLP, in: Actas del IV Simp. CEA Model. Simulación y Optim., Valladolid, Spain, 2018, pp. 78-83, [In Spanish].

[36] Spanish Ministry of Industry, Tourism and Commerce, Royal Decree 1544/2011, on 31 October, establishing the transport and distribution network access fees to be paid by electricity producers, [Online]. Available: https://www.boe.es/boe/dias/ 2011/11/16/pdfs/BOE-A-2011-17891.pdf, Accessed on: Mar. 14, 2018.

[37] Head of State, Law 15/2012, of 27th December, on tax measures for energy sustainability, [Online]. Available: https://www. boe.es/boe/dias/2012/12/28/pdfs/BOE-A-2012-15649.pdf, Accessed on: Mar. 14, 2018.

[38] Spanish Ministry of Energy, Tourism and Digital Diary, Error correction of the Order ETU/1282/2017, of 22nd December, establishing electricity access fees for 2018, [Online]. Available: https://www.boe.es/boe/dias/2017/12/28/pdfs/ BOE-A-2017-15608.pdf, Accessed on: Mar. 14, 2018.

[39] OMI-Polo Español S.A. (OMIE), OMIE web site, [Online]. Available: http://www.omie.es/en/inicio, Accessed on: Mar. 14, 2018.

[40] Red Eléctrica de España, S.A. (REE), REE web site, [Online]. Available: http://www.ree.es/en, Accessed on: Mar. $14,2018$.

[41] EPEX SPOT, Nord Pool, OMIE, OPCOM, GME, OTE, TGE (PCR PXs), Euphemia public description. PCR market coupling algorithm, [Online]. Available: https://www.nordpoolspot.com/globalassets/download-center/pcr/ euphemia-public-documentation.pdf, Accessed on: Mar. 14, 2018.

[42] J. A. Carballo, J. Bonilla, L. Roca, A. de la Calle, P. Palenzuela, M. Berenguel, Optimal operating conditions analysis of a multi-effect distillation plant, Desalin. Water Treat. 69 (2017) 229-235.

[43] J. A. Duffie, W. A. Beckman, Solar Engineering of Thermal Processes, John Wiley \& Sons, Inc., Hoboken, NJ, USA, 2013.

[44] J. Ramos-Teodoro, F. Rodríguez, M. Berenguel, Photovoltaic facilities modelling for an energy hub with heterogeneous resources management, in: Actas del XVI Simp. CEA Ing. Control, Almeria, Spain, 2018, pp. 23-30, [In Spanish].

[45] M. Pasamontes, J. Álvarez, J. Guzmán, M. Berenguel, Hybrid modeling of a solar cooling system, IFAC Int. Conf. Anal. Des. Hybrid Syst. ADHS09 3 (1) (2009) 26-31.

[46] L. Roca, M. Berenguel, L. Yebra, D. C. Alarcón-Padilla, Solar field control for desalination plants, Sol. Energy 82 (9) (2008) $772-786$.

[47] Endesa S.A., Latest electricity and gas rates, [Online]. Available: https://www.endesaclientes.com/articles/ latest-gas-light-regulated-rates.html, Accessed on: Mar. 14, 2018.

[48] Spanish Biomass Association (AVEBIOM), Biomass prices index, [Online]. Available: http://www.avebiom.org/es/ ind-precios-biomasa, Accessed on: Mar. 14, 2018.

[49] Profielectra S.L, Propane price, [Online]. Available: https://propanogas.com/faq/precio-propano, Accessed on: Mar. 14, 2018.

[50] FCC AQUALIA, Water tariffs, [Online]. Available: http://www.aqualia.com/es/web/aqualia-almeria/atencion-al-cliente/ tarifas-de-agua, Accessed on: Mar. 14, 2018.

[51] The MathWorks Inc., Documentation: intlinprog, [Online]. Available: https://es.mathworks.com/help/optim/ug/intlinprog. html, Accessed on: Mar. 14, 2018.

[52] G. T. Ayele, P. Haurant, B. Laumert, B. Lacarrière, An extended energy hub approach for load flow analysis of highly coupled district energy networks: Illustration with electricity and heating, Appl. Energy 212 (2018) 850-867. 